Hydrocolloids

Elsevier Editorial System(tm) for Food

Manuscript Draft

Manuscript Number: FOODHYD-D-16-00275R1

Title: Novel antimicrobial zein film for controlled release of lauroyl arginate (LAE)

Article Type: Research Paper

Keywords: Antimicrobial packaging; bioplastics; LAE; zein; antimicrobial release; release kinetics.

Corresponding Author: Dr. Rafael Gavara, Ph.D.

Corresponding Author's Institution: IATA-CSIC

First Author: Mahboobeb Kashiri

Order of Authors: Mahboobeb Kashiri; Josep P Cerisuelo, PhD; Irene Dominguez, PhD; Gracia Lopez-Carballo, PhD; Pilar Hernandez-Muñoz, PhD; Rafael Gavara, Ph.D.

Abstract: Novel antimicrobial biopolymer films based on the incorporation of ethyl-No-dodecanoyl-L-arginate hydrochloride (LAE) in zein matrices were manufactured and characterized as materials for LAE controlled released applications such as active food packaging. Characterization of the films' functional properties revealed that incorporation of LAE (5 and $10 \%$ ) in the biopolymer matrix did not cause substantial changes in morphological, optical, thermal, mechanical and barrier properties. As the mechanism of action of these films is mainly based on release of the antimicrobial, this process was characterized when the active biofilms were exposed to three food simulants (water, 3\% acetic acid, and 10\% alcohol) at three temperatures $\left(4,23\right.$, and $\left.37{ }^{\circ} \mathrm{C}\right)$. The data obtained revealed that, with the exception of exposure to water at $4{ }^{\circ} \mathrm{C}$ which achieved a release of more than $80 \%$ of the LAE incorporated, the agent was almost completely extracted in all conditions. Release of LAE was faster at higher temperatures, and the diffusion coefficient values varied according to the Arrhenius law, and increased with temperature. Antibacterial activity of films was assayed against L. monocytogenes and E. coli. Zein films with 5\% LAE produced 2.02 and 3.07 log reduction against L. monocytogenes and E. Coli, respectively, after 5 days of storage at $4{ }^{\circ} \mathrm{C}$. Greater antibacterial activity was observed with films containing $10 \%$ LAE ( 5 log reduction) at $37^{\circ} \mathrm{C}$. This work highlighted that LAE incorporation in a packaging film constructed with renewable polymer materials offers an interesting and efficient hurdle for control of bacterial contamination in foods. 


\section{Novel antimicrobial zein film for controlled release of lauroyl arginate (LAE)}

2 Mahboobeb Kashiri ${ }^{1}$, Josep P. Cerisuelo, Irene Domínguez, Gracia López-Carballo, Pilar 3 Hernández-Muñoz, Rafael Gavara*

4 Packaging Lab, Instituto de Agroquímica y Tecnología de Alimentos, CSIC, Av. Agustín $5 \quad$ Escardino 7, 46980 Paterna (SPAIN), rgavara@iata.csic.es

$6{ }^{1}$ Present address: Department of Food Science and Technology, Gorgan University of 7 Agricultural Sciences and Natural Resources, Beheshti Ave., Gorgan 49138-15739, Iran

8

9 
Abstract

Novel antimicrobial biopolymer films based on the incorporation of ethyl- $\mathrm{N}^{\alpha}$-dodecanoyl-Larginate hydrochloride (LAE) in zein matrices were manufactured and characterized as materials for LAE controlled released applications such as active food packaging. Characterization of the films' functional properties revealed that incorporation of LAE (5 and 10\%) in the biopolymer matrix did not cause substantial changes in morphological, optical, thermal, mechanical and barrier properties.

As the mechanism of action of these films is mainly based on release of the antimicrobial, this process was characterized when the active biofilms were exposed to three food simulants (water, $3 \%$ acetic acid, and $10 \%$ alcohol $)$ at three temperatures $\left(4,23\right.$, and $\left.37^{\circ} \mathrm{C}\right)$. The data obtained revealed that, with the exception of exposure to water at $4{ }^{\circ} \mathrm{C}$ which achieved a release of more than $80 \%$ of the LAE incorporated, the agent was almost completely extracted in all conditions. Release of LAE was faster at higher temperatures, and the diffusion coefficient values varied according to the Arrhenius law, and increased with temperature. Antibacterial activity of films was assayed against L. monocytogenes and E. coli. Zein films with 5\% LAE produced 2.02 and $3.07 \log$ reduction against L. monocytogenes and E. coli, respectively, after 5 days of storage at $4{ }^{\circ} \mathrm{C}$. Greater antibacterial activity was observed with films containing $10 \%$ LAE (5 log reduction) at $37{ }^{\circ} \mathrm{C}$. This work highlighted that LAE incorporation in a packaging film constructed with renewable polymer materials offers an interesting and efficient hurdle for control of bacterial contamination in foods.

Keywords: Antimicrobial packaging, bioplastics, LAE, zein, antimicrobial release, release kinetics.

\section{INTRODUCTION}

Post-processing contamination is one of the major causes of foodborne illness and of the associated food product recalls, and is becoming a major public health issue and an economic burden for the food industry. Within the technologies developed to avoid this problem, active packaging incorporating antimicrobial substances is one of the most promising methods in 
quality (reducing the incidence of spoilage microorganisms) (Gavara, et al., 2015). Direct addition of active agent may cause rapid diffusion of the antimicrobial into the food matrix and partial inactivation by interaction with product constituents. As an alternative, active packaging can offer slow, continuous release of antimicrobial agents from polymer packaging materials to food surfaces, thus maintaining an adequate concentration during storage and distribution, concentrated on the food surface where the antimicrobials are generally most needed (Arancibia, Lopez-Caballero, Gomez-Guillen, \& Montero, 2014; Barbiroli, et al., 2012; Muriel Galet, et al., 2013).

There is a large number of antimicrobial compounds that have been proved to inhibit the growth of pathogenic and spoilage microorganisms present in food. One that is receiving particular attention is a novel molecule, ethyl- $\mathrm{N}^{\alpha}$-dodecanoyl-L-arginate hydrochloride (LAE). The antimicrobial properties of LAE are due to its action as a cationic surfactant on the cytoplasm and outer membrane of Gram-negatives, and the cell membrane and cytoplasm of Gram-positives, resulting in cell growth inhibition and loss of viability (Luchansky, et al., 2005). In addition to the good antimicrobial properties of LAE, this molecule remains stable from $\mathrm{pH} 3$ to $\mathrm{pH} 7$ and does not add flavor, suggesting that this substance may be useful as an antimicrobial agent for a wide range of foods (Becerril, Manso, Nerin, \& Gómez-Lus, 2013). Moreover, LAE is hydrolyzed in the human body and transformed into natural components such as arginine and lauric acid (Hawkins, Rocabayera, Ruckman, Segret, \& Shaw, 2009), and is considered as a safe product and permitted as a food preservative by the Food and Drug Administration (FDA) and the European Food Safety Agency (EFSA).

LAE has been successfully incorporated into conventional polymer (Virginia Muriel-Galet, et al., 2012; Otero, et al., 2014) and into biopolymeric chitosan (Guo, Jin, Wang, Scullen, \& Sommers, 2014; Guo, Jin, \& Yang, 2014) film coatings to inhibit various pathogenic bacteria. With respect to biopolymers, growing environmental concern about the use of packaging materials is driving the food industry and packaging manufacturers to explore the use of alternative biopolymers in all packaging technologies, including active packaging (Petersen, et al., 1999). Among these biopolymers, many efforts are being focused on animal and vegetable proteins. Zein (the major storage protein in corn endosperm) is a very attractive packaging material because it is the main residue from production of corn starch, is commercially available, and is soluble in hydroalcoholic mixtures from which it can be easily converted into transparent films with attractive properties due to high content of nonpolar amino acids (Matsushima, Danno, Takezawa, \& Izumi, 1997), such as good moisture barrier, 
and excellent oxygen barrier (Gioia \& Guilbert, 1999; Ozcalik \& Tihminlioglu, 2013). Taking advantage of the film-forming solution, several antioxidant and antimicrobial agents have been successfully incorporated in zein films, such as butylated hydroxyanisole BHA (Herald, Hachmeister, Huang, \& Bowers, 1996), nisin (Janes, Kooshesh, \& Johnson, 2002), salicylic acid, acetyl salicylic acid (Singh, Georget, Belton, \& Barker, 2010), or thymol (del Nobile, Conte, Incoronato, \& Panza, 2008; Mastromatteo, Barbuzzi, Conte, \& Del Nobile, 2009).

The main objective of this study was the development and characterization of zein films containing 5 and $10 \%$ of LAE. The characterization included optical, mechanical, and barrier properties, studies of antimicrobial release into aqueous food simulants at 4 and $37{ }^{\circ} \mathrm{C}$, and antimicrobial activity.

\section{MATERIALS AND METHODS}

\subsection{Reagents and microbial strains}

Decolored and deodorized Kobayashi zein powder was purchased from CBC-Iberia (Barcelona). Ethyl- $\mathrm{N}^{\alpha}$-dodecanoyl-L-arginate hydrochloride $\left(\mathrm{C}_{20} \mathrm{H}_{41} \mathrm{~N}_{4} \mathrm{O}_{3} \mathrm{Cl}\right)$ was kindly provided by Vedeqsa Grupo LAMIRSA (Terrassa, Barcelona, Spain). Ethanol, acetic acid, and acetonitrile were purchased from Scharlau (Barcelona, Spain), and trifluoroacetic acid and glycerol from Sigma (Madrid, Spain). These reagents were used without further purification. Deionized water was supplied by a Millipore Milli-Q Plus purification system (Molsheim, France).

Gram-positive bacteria, Listeria monocytogenes CECT 934 (ATCC 19114), and Gramnegative bacteria, Escherichia coli CECT 434 (ATCC 25922), were obtained from the Spanish Type Culture Collection (CECT, Valencia, Spain) and selected for use in the antimicrobial assays because of their relevance in the food industry. The strains were stored in Tryptone Soy Broth (TSB, Scharlau, Barcelona) with $20 \%$ glycerol at $-80{ }^{\circ} \mathrm{C}$ until needed. For experimental use, the stock cultures were maintained by regular subculture on Tryptone Soy Agar (TSA) slants from Scharlau (Barcelona, Spain) at $4{ }^{\circ} \mathrm{C}$ and transferred monthly. Prior to tests, a loop of each strain was transferred to $10 \mathrm{ml}$ of TSB and incubated at $37^{\circ} \mathrm{C}$ for $18 \mathrm{~h}$ to obtain early stationary phase cells.

\subsection{Film preparation}


Sixteen $\mathrm{g}$ of zein powder was added to $84 \mathrm{~g}$ of hydroalcoholic solution $(80 \% \mathrm{v} / \mathrm{v})$ with continuous stirring at $70{ }^{\circ} \mathrm{C}$ until complete dissolution, and then cooled down to $40{ }^{\circ} \mathrm{C}$. Owing to the fragility of the zein film, the addition of glycerol as plasticizer was required; otherwise, the film was too fragile to be handled. After preliminary trials (not included in this report and in agreement with previous reports (Liang, et al., 2015; Naushad Emmambux \& Stading, 2007)) to select the minimum concentration required to obtain films flexible enough to be handled without breaking, $15 \%$ of glycerol (w/w of zein) was added to the solution and it was stirred for another $8 \mathrm{~min}$ at $40{ }^{\circ} \mathrm{C}$. Finally, LAE was added to the polymer solutions at 5 or $10 \%$ with respect to zein content and they were stirred for another $8 \mathrm{~min}$. Film-forming solutions were spread on a clean glass plate, using a spreading bar with a thread $250 \mu \mathrm{m}$ deep (LinLab, Logroño, Spain), and dried in a forced-air drying tunnel equipped with a $2500 \mathrm{~W}$ IR heat source for $20 \mathrm{~min}$. Then the films were peeled off and stored in desiccators with silica gel until tested. Control films were prepared without the active agent. Film thickness was determined individually with a digital micrometer (Mitutoyo, Kanagawa, Japan) prior to testing.

\subsection{Film characterization}

\subsubsection{Morphology and optical properties}

The morphology of the zein films was analyzed by observation of the cryo-fracture surface by scanning electron microscopy (SEM). The film color was determined with a colorimeter and the results were expressed in the CIELAB system, and the opacity was estimated by measuring the transmittance in a UV-visible spectrophotometer. A complete description of the procedures used is included in the supplementary material.

\subsubsection{Fourier-transform infrared (FTIR) spectroscopy}

The IR spectra of the films were determined using an infrared spectrometer (FTIR) (Perkin Elmer 16 PC spectrometer, Boston, USA), in Attenuated Total Reflectance mode (ATR) between 400 and $4000 \mathrm{~cm}^{-1}$, using 16 scans at a resolution of $4 \mathrm{~cm}^{-1}$.

\subsubsection{Differential scanning calorimetry (DSC)}

Differential scanning calorimetry (DSC) measurements were performed with a Q2000 unit (TA Instruments, USA). Samples were cooled down to $-60{ }^{\circ} \mathrm{C}$, and after 5 min they were heated to $220{ }^{\circ} \mathrm{C}$ at a heating rate of $10{ }^{\circ} \mathrm{C} \mathrm{min}^{-1}$ under a nitrogen atmosphere.

\subsubsection{Mechanical properties}


After at least 24 hours of film preconditioning at $50 \pm 5 \% \mathrm{RH}$ and room temperature, tensile strength (TS), percentage of elongation at break (EB), and Young's modulus (YM) of the films were determined using a Mecmesin MultiTest 1-I universal machine (Landes Poli Ibérica, S.L., Barcelona, Spain), following the conditions of the ASTM D882 standard (ASTM, 2009).

\subsubsection{Mass transport properties}

\subsubsection{Water solubility}

Samples of films $(2 \times 2 \mathrm{~cm})$ were dried in a desiccator containing phosphorus pentoxide for one week to reach constant weight $\left(\mathrm{w}_{i}\right)$, and then immersed in aqueous solution buffered at $\mathrm{pH} 5$ at $23{ }^{\circ} \mathrm{C}$. After $24 \mathrm{~h}$, film pieces were removed from the solution, wiped off with a paper towel, and dried in the desiccator until constant weight (final weight, $\mathrm{w}_{f}$ ). The percentage of water solubility (WS) was calculated as follows:

$$
W S(\%)=\frac{w_{i}-w_{f}}{w_{i}} \cdot 100
$$

The experiment was performed in triplicate.

\subsubsection{Water vapor permeability (WVP)}

The water vapor permeability of the films was determined gravimetrically at $25{ }^{\circ} \mathrm{C}$ according to ASTM E96-95 (ASTM, 2010), with a humidity gradient of 75\% RH to 0\% RH and 100\% $\mathrm{RH}$ to $0 \% \mathrm{RH}$.

\subsubsection{Oxygen permeability}

The measurements of $\mathrm{O}_{2}$ and $\mathrm{CO}_{2}$ permeance through the film samples were carried out using isostatic methods (Cerisuelo, Gavara, \& Hernández-Muñoz, 2015).

\subsubsection{Release studies of active zein films}

The release of the active compound from the zein films was investigated by immersing film samples measuring $3 \mathrm{~cm}^{2}$ into $5 \mathrm{~mL}$ of food simulants. Water, acetic acid $(3 \% \mathrm{v} / \mathrm{v})$, and ethanol $(10 \% \mathrm{v} / \mathrm{v})$ were used as food simulants, in accordance with European legislation (Directive 58/572/ECC). Sample tubes were stored at 4 and $37{ }^{\circ} \mathrm{C}$ under gentle agitation. Pieces of film were removed from the food simulants at different time intervals and the liquid was collected for analysis. Liquid samples were filtered and the concentration of LAE released was evaluated by HPLC (Agilent 1200 series). The chromatographic column used was a $\mathrm{C}_{18}$ reverse phase column, $150 \mathrm{~mm} \times 3.9 \mathrm{~mm}$, particle size $5 \mu \mathrm{m}$. The mobile phase 
was acetonitrile:water 50:50 (v/v) containing $0.1 \%$ trifluoroacetic acid at a flow rate of 1 $\mathrm{mL} / \mathrm{min}$, and the injection volume was $20 \mu \mathrm{L}$. The LAE elution time was about 6 min and it was detected using a wavelength of $205 \mathrm{~nm}$. A calibration curve was constructed by injection of known LAE concentrations between 5 and $100 \mathrm{ppm}$. From the concentration evolution, the partition coefficient $(K)$, defined as the ratio of LAE concentration in the film over concentration in the simulant, and the diffusion coefficient $(D)$ as defined by Fick's laws were estimated. The procedure for determining these two coefficients is fully described in the supplementary file.

\subsubsection{Evaluation of antimicrobial activity of zein films with LAE in a liquid medium}

To evaluate the antimicrobial efficacy of the zein films incorporating 5 and 10\% LAE, they were against $E$. coli and L. monocytogenes. Prior to the experiment, a loop of each strain was transferred to $10 \mathrm{~mL}$ of TSB and incubated at $37{ }^{\circ} \mathrm{C}$ for $18 \mathrm{~h}$ to obtain early stationary phase cells. Cell cultures of each microorganism in stationary phase, with an optical density of 0.9 at $600 \mathrm{~nm}$, were diluted in TSB and incubated at $37{ }^{\circ} \mathrm{C}$ until exponential phase, corresponding to an optical density of 0.2 at $600 \mathrm{~nm}\left(10^{5} \mathrm{CFU} / \mathrm{ml}\right)$. One hundred $\mu \mathrm{L}$ of exponential phase microorganism was inoculated into tubes with $10 \mathrm{~mL}$ of TSB. A $0.025 \mathrm{~g}$ portion of film (cut into pieces measuring $1.5 \mathrm{~cm}^{2}$ ) was added to each tube in sterile conditions. The tubes were then incubated at $37{ }^{\circ} \mathrm{C}$ for $18 \mathrm{~h}$ and $4{ }^{\circ} \mathrm{C}$ for 5 days. As a control, zein film without active agent was also used in every experiment. Depending on the turbidity of the tubes, serial dilutions with peptone water were made and plated in Petri dishes with 15 $\mathrm{mL}$ of TSA culture medium. Colonies were counted after incubation at $37^{\circ} \mathrm{C}$ for $18 \mathrm{~h}$.

\subsubsection{Statistical analysis}

Statistical analysis of the results obtained was performed with the aid of IBM SPSS Statistics 21 commercial software (IBM Corp., Armonk, NY, USA). Specifically, a one-way analysis of variance (ANOVA) was carried out, and differences found between mean values for the materials studied were assessed by means of confidence intervals, using Tukey's test at a $\mathrm{p} \leq$ 0.05 level of significance.

\section{RESULTS AND DISCUSSION}

In this work, a decolored deodorized zein was used to obtain films by the casting procedure described in the experimental section. Passive and active zein films were transparent to visible light although partially opaque to UV light owing to the high content of aromatic 
amino acids which absorb UV light (Hosseini, Rezaei, Zandi \& Ghavi, 2013), slightly yellowish, with chroma values of ca. 7 (despite the type of zein used), and practically odorless compared with standard zein, which smells strongly of animal feed. Morphologically, the film matrix was homogeneous, without phase separation and without substantial differences between active and control samples. All film formulations included $15 \%$ of glycerol, which was required to reduce brittleness and ease handling. Mechanically, the films presented low resistance to strain. A fuller description of optical and mechanical properties is provided in the supplementary material.

\subsection{Thermal properties}

The thermal properties of pure zein powder and plasticized zein film with and without the antimicrobial agents were measured by DSC and are presented in Figure 1. The thermogram for pure zein shows a high glass transition temperature $(\mathrm{Tg})$ of about $132{ }^{\circ} \mathrm{C}$, close to the 139 ${ }^{\circ} \mathrm{C}$ value reported in the literature (Madeka \& Kokini, 1996). This expected value is also in agreement with the fragility observed in pure films during preliminary assays. After plasticization with $15 \%$ of glycerol, the glass transition of the prepared zein films decreases to values of $57{ }^{\circ} \mathrm{C}$, close to values observed in other reports for zein films plasticized with various percentages of glycerol (di Gioia \& Guilbert, 1999; Ghanbarzadeh, Oromiehie, Musavi, Razmi, \& Milani, 2006). When the plasticized film is immersed in water, the film is highly plasticized and swells (Madeka, et al., 1996), and the glycerol diffuses rapidly in the polymer matrix and dissolves in the liquid medium. When the film is re-dried and the water removed, the final film does not contain any plasticizer. The glass transition of such films (Zein-G-Water in Figure 1) was found at $153{ }^{\circ} \mathrm{C}$, even higher than that of the powder. This value might be caused by the removal of other residues in the zein powder, which might affect the glass transition of the pure polymer. The addition of LAE at 5 and $10 \%$ to the plasticized film did not produce any substantial effect on the $\mathrm{Tg}$, as can be seen in Figure 1. Also, in the film samples (Zein-G, Zein-G-5\%LAE, and Zein-G-10\%LAE), two endotherms can be observed, at ca. 100 and $160{ }^{\circ} \mathrm{C}$, which are associated with the evaporation of residual solvent and of glycerol, respectively.

\subsection{Barrier properties}

Barrier properties are important to protect packaged products from the environment and maintain their quality for longer storage times. The barrier properties of polymer films are 
generally related to the physical and chemical nature of the polymers. This section deals with the evaluation of water vapor, oxygen, and carbon dioxide permeability of zein-based films.

\subsubsection{Water vapor permeability (WVP)}

Water transport in food packaging can accelerate food spoilage mechanisms such as browning, lipid oxidation, vitamin degradation, enzyme activity, microbial growth, and textural changes, reducing food shelf life and quality. Thus, water permeability is a critical parameter for packaging materials. In this work, water flow through the film into the cell was measured at humidity gradients of $70 \%$ and $90 \%$. The evolution of cell weight shown in the left plot of Figure 2 shows that the water flow increases with the gradient, as expected, because the gradient is the driving force of the mass transport phenomena. From the slopes in this representation $(\mathrm{dm} / \mathrm{dt})$ and the film thickness $(L)$ and the vapor pressure gradient $\left([\Delta R H] \cdot p_{v}\right)$, the WVP values (right plot of Figure 2$)$ were estimated.

$$
W V P=\frac{\left(\frac{d m}{d t}\right) \cdot L}{\left(A \cdot t \cdot[\Delta R H] \cdot p_{v}\right)}=
$$

WVP values for the control zein film were 3.7 and $5.5 \times 10^{-14} \mathrm{Kg} \cdot \mathrm{m} /\left(\mathrm{m}^{2} \cdot \mathrm{s} \cdot \mathrm{Pa}\right)$ at $70 \%$ and $90 \%$ relative humidity, respectively, slightly lower than the values reported in the literature (McHugh \& Krochta, 1994). In hydrophobic materials, WVP is usually not influenced by the humidity gradient. However, hydrophilic materials suffer swelling and plasticization with the presence of water, and these processes result in an increase in WVP values with exposure to humidity. As can be seen in Figure 2, water permeability values increased with the humidity to which the film was exposed. Even though zein is less hydrophilic than other protein materials, such as whey or gluten, the water gained by the film upon exposure to high humidity environments results in film plasticization, and, as in many other hydrocolloid materials, the barrier characteristics worsen (McHugh, et al., 1994). Statistical analysis of the results showed that the addition of $10 \%$ LAE could reduce water permeability of the films, this effect being more evident at high water activities. The ambiphilic properties of LAE as surfactant are probably responsible for this effect, limiting the swelling effect of water and maintaining the zein interchain interactions even when exposed to wet environments (Figure 2). 
259

260

261

262

263

264

265

266

267

268

269

270

271

272

273

274

275

276

277

278

279

280

281

282

283

284

285

286

287

Oxygen barrier was measured for the three zein-based film samples equilibrated at three humidity conditions and the oxygen permeability values are plotted in Figure 3. Dry samples presented a good barrier to oxygen, similar to the values reported in the literature (McHugh, et al., 1994), i.e., a much better barrier than commodity plastics such as PE or PP, and in the range of engineering materials such as PET or PA6. When the films were equilibrated at increasingly humid environments, their oxygen permeability increased greatly, 4 -fold at $70 \%$ $\mathrm{RH}$ and 30 -fold at $90 \%$. This observation was in agreement with the matrix plasticization by sorbed water mentioned earlier. On comparing the various samples, no significant differences could be attributed to the addition of LAE.

Carbon dioxide permeability is also important in food packaging systems because this gas is a major component of modified atmosphere packaging systems and is exchanged by fresh fruit and vegetables during the postharvest period. Values of the carbon dioxide permeability presented the same profile as oxygen permeability. The zein films presented a CO2P of $5.4 \pm$ $1.2 \cdot 10^{-19}, 2.1 \pm 0.4 \cdot 10^{-18}$, and $2.0 \pm 0.6 \cdot 10^{-17}\left[\mathrm{~m}^{3} . \mathrm{m}\right] /\left[\mathrm{m}^{2} . \mathrm{s} . \mathrm{Pa}\right]$ at 0,70 , and $90 \% \mathrm{RH}$, respectively, without differences caused by the incorporation of LAE. Compared with oxygen mass transport, carbon dioxide permeates about 4 times faster, similar to most conventional oil-based polymers, and unlike other hydrocolloid films, whose permselectivity (CO2P/OP) increases with humidity up to 20-fold (Balaguer, Cerisuelo, Gavara, \& Hernandez-Munoz, 2013).

\subsubsection{Water solubility (WS)}

From a traditional point of view, ideal packaging should present negligible interactions with the contained product. Although this characteristic has changed with the development of active and intelligent packaging, food/package/environment mass exchange processes should be limited to those that actually provide a beneficial effect on product preservation. One of the largest interactions taking place in a food/flexible package system is derived from partial dissolution of the polymer matrix. This process is especially important with aqueous foods and packaging materials based on hydrocolloids. Water resistance and integrity are required for packaging foods with high moisture contents, and partial dissolution might be disadvantageous. Contrary to a previous report (Yamada, Takahashi, \& Noguchi, 1995) films were water resistant and maintained integrity in water throughout the diverse tests carried out 
in this work. The WS values of the prepared zein films were $12.8 \pm 1.4$ for the Zein-G films, $17.7 \pm 0.3$ for Zein-G-5\%LAE, and $22.6 \pm 0.6 \%$ for Zein-G-10\%LAE. To understand this result, our hypothesis is that the principal migrant is glycerol (a highly water-soluble plasticizer). As this compound is practically at the same final concentration in all the films, i.e., ca. $15 \%$, it can be considered that most of the glycerol added is released into the aqueous medium. Obviously, LAE, which is also water-soluble, should also be partially released, being part of the WS values. Compared with other hydrocolloids often reported as alternative materials to oil-based polymers for film applications, such as gelatin (WS=63.81\%) (Hosseini, Rezaei, Zandi, \& Ghavi, 2013), chitosan (WS=31.64\%) (Martins, Cerqueira, \& Vicente, 2012), alginate (WS=99.5\%) (Abdollahi, Alboofetileh, Behrooz, Rezaei, \& Miraki, 2013), and kefiran (WS=27.91\%), it can be considered that zein is practically insoluble in water. This behavior can be explained by the fact that $50 \%$ of zein amino acid residues are hydrophobic, including high percentages of leucine (20\%), proline (10\%), and alanine (10\%) (Cabra, et al., 2005; Geraghty, Peifer, Rubenstein, \& Messing, 1981).

The increase in WS with the incorporation of LAE is clearly related to the full release of the antimicrobial agent into the aqueous medium. This hypothesis is in agreement with the release values described in the next section.

\subsection{Antimicrobial agent release}

The mechanism of action of antimicrobial food packaging systems like the one developed in this work is based on the release of an antimicrobial compound from the packaging film into the food product. Consequently, it is important to characterize the substance released into the food. To carry out this study, the films were exposed to three food simulants, water and the two food simulants recommended by EU regulations, $10 \%$ ethanol as a simulant of aqueous food, and 3\% acetic acid as a simulant of acid products. The release of LAE was monitored until a constant concentration was observed. Three exposure temperatures were included, 4 ${ }^{\circ} \mathrm{C}$ to simulate refrigerated storage, $23{ }^{\circ} \mathrm{C}$ to simulate room temperature (as in supermarkets), and $37^{\circ} \mathrm{C}$ to simulate temperature abuse conditions (non-conditioned warehouses or trucks).

Figure 4 is a representative plot of the results obtained for a simulant. As can be seen, the data can be described by exponential growth to maximum profiles. From the data at equilibrium, the $K$ values were obtained for all samples and conditions. From the data during the non-equilibrium period, the values of $D$ were evaluated by curve fitting as described in 
the supplementary material. Figure 4 also includes the curves obtained with the $K$ and $D$ data that provide the best fit, data that are represented in Figure 5. As the concentration of LAE is assumed not to affect the process substantially, the data of samples with 5 and $10 \%$ of LAE were considered together in the curve fitting process. As Figure 4 shows, this assumption is easily acceptable. The $K$ values obtained were very low; the highest values were obtained for water at $4{ }^{\circ} \mathrm{C}(K=7.5)$ and $10 \%$ ethanol at $4{ }^{\circ} \mathrm{C}(K=5.5)$. The rest of the $K$ values were below 1. From these data, the percentages of LAE release from the films into the simulant were calculated, and they are represented in Figure 5 together with the values of $D$. As can be seen, the amount of antimicrobial substance released increases with temperature, and, with the exception of exposure to water at $4{ }^{\circ} \mathrm{C}$, which results in a release of about $82 \%$, the release is almost complete for all other conditions.

With respect to the process kinetics, temperature severely affects the release rate, as can be seen in the experimental data and the theoretical curves plotted in Figure 4. The values of the diffusion coefficient obtained through this fitting are represented as a function of the inverse of temperature in Figure 5. For the three simulants, this representation of the Arrhenius plot approaches a linear plot from which the activation energies for the diffusion of LAE can be obtained and they are included in the figure. With respect to the effect of the simulants, few differences were observed. In general, exposure to the acid simulant results in greater release of the agent from the polymer film at all temperatures, and the release is also faster than with the other simulants, especially at low temperatures. Very similar profiles were observed for water and $10 \%$ ethanol. There is a significant difference in the percentage of agent released from the film at 4 and $23{ }^{\circ} \mathrm{C}$. Apparently, the presence of the alcohol shifts the equilibrium toward the liquid phase. No effect on the kinetics was observed at these temperatures.

The release of LAE from other polymer materials has been characterized previously. Our team studied the release from two hydrophilic polymers, chitosan (Higueras, López-Carballo, Hernández-Muñoz, Gavara, \& Rollini, 2013) and EVOH (V. Muriel-Galet, López-Carballo, Hernández-Muñoz, \& Gavara, 2014). From comparison of the results we can conclude that LAE is released more slowly from zein films than from chitosan or EVOH. This more controlled release might be related to the fact that zein is less hydrophilic than those two polymers and therefore sorbs less water. This lower water gain results in less matrix swelling and plasticization, and consequently slower LAE diffusion. 
Table 1 shows the results of the antibacterial activity analysis carried out on the zein films incorporating 5 and $10 \%$ LAE by exposing them to L. monocytogenes and E. coli inoculated in TSB tubes at 37 and $4{ }^{\circ} \mathrm{C}$. Zein film without LAE was used as control (a previous analysis not reported here proved that plasticized zein has no bactericidal or bacteriostatic effect). The listericidal results of zein films containing 5 and 10\% LAE showed a 2.61 and $4.99 \log$ reduction, respectively, after $18 \mathrm{~h}$ of exposure at $37^{\circ} \mathrm{C}$. These film samples containing 5 and $10 \%$ of LAE also yielded 2.95 and $4.16 \log$ reductions against E. coli in the same conditions. Clearly, the higher the LAE concentration in the film, the greater the antimicrobial efficiency of the zein film, a trend that is in agreement with the greater amount of LAE released into the culture medium. Similar growth inhibition was observed after exposure at $4{ }^{\circ} \mathrm{C}$ for 5 days. This result is also in agreement with the release process observed. After 5 days, practically all the agent had been released into all the food simulants studied, and therefore the LAE contents to which the microorganisms were exposed in these conditions were similar to those to which they were exposed after $18 \mathrm{~h}$ at $37{ }^{\circ} \mathrm{C}$. The activity results obtained here showed that LAE-containing zein films are less efficient than chitosan (Higueras, et al., 2013) or EVOH films (V. Muriel-Galet, Lopez-Carballo, Gavara, \& Hernandez-Munoz, 2015). This can be attributed to the slower agent release mentioned earlier.

Considering that the experimental conditions used for the antimicrobial effect analysis were similar to those used in the release study, that is same film/liquid ratio, the amount of LAE release into the media should be similar to that observed in water at 4 and $37^{\circ} \mathrm{C}$, that is $82 \%$ and $100 \%$, respectively. This release percentage are indicative of an agent concentration in the broth after equilibrium of 100-125 ppm for the 5\% LAE film and 200-250 ppm for the $10 \%$ LAE. To prove the effectiveness of antimicrobial films as vehicle to release an agent with respect to the agent direct addition, a simple experiment was made by adding LAE to the TSB tubes containing E. coli. at 50, 100 and $200 \mathrm{ppm}$. The results were 2.82, 5,03 and 5,38 log reductions, respectively. A simple comparison shows that the use of the film provides slightly lesser effect than the direct addition, probably because the controlled release delays the achievement of the final agent dose.

\section{CONCLUSIONS}


Zein has been proved to be an excellent vehicle for delivering LAE, a novel wide-spectrum antimicrobial agent, into food products and for improving the stability and safety of food. LAE (5 and 10\%) was incorporated in glycerol-plasticized zein films prepared by casting. The resulting films presented good barrier properties against oxygen and carbon dioxide and a poor barrier to water. Although the films were stable when immersed in water and did not degrade, as occurs with many other protein films, these properties were substantially affected by water. The incorporation of the antimicrobial agent did not affect optical, thermal, barrier, or mechanical properties of the zein films. When the films were immersed in aqueous food simulants, LAE was released to a large extent or nearly completely at a fast rate which was accelerated by an increase in temperature. Antimicrobial tests carried out on these films showed that they are efficient at inhibiting the growth of L. monocytogenes and E. coli. The material developed could be applied as a coating to a biopolymer film to provide a renewable packaging structure with antimicrobial properties.

\section{ACKNOWLEDGMENTS}

The authors acknowledge the financial support of the Spanish Ministry of Economy and Competitiveness, projects AGL2012-39920-C03-01. M.K. thanks the Ministry of Sciences, Research and Technology of Iran for her grant. I.D. thanks the CSIC for her postdoctoral contract (JAE-DOC). The authors are also grateful to Karel Clapshaw for language services.

\section{References}

Abdollahi, M., Alboofetileh, M., Behrooz, R., Rezaei, M., \& Miraki, R. (2013). Reducing water sensitivity of alginate bio-nanocomposite film using cellulose nanoparticles. International Journal of Biological Macromolecules, 54(0), 166-173.

Arancibia, M. Y., Lopez-Caballero, M. E., Gomez-Guillen, M. C., \& Montero, P. (2014). Release of volatile compounds and biodegradability of active soy protein lignin blend films with added citronella essential oil. Food Control, 44, 7-15.

ASTM. (2009). Standard test method for tensile properties of thin plastic sheeting D882-02. In ASTM, Annual Book of American Standard Testing Methods. Philadelphia, PA.

ASTM. (2010). ASTM E96 / E96M - 10. Standard Test Methods for Water Vapor Transmission of Materials. In (Vol. ASTM E96 / E96M - 10). West Conshohocken, PA,: ASTM International.

Balaguer, M. P., Cerisuelo, J. P., Gavara, R., \& Hernandez-Munoz, P. (2013). Mass transport properties of gliadin films: effect of cross-linking degree, relative humidity, and temperature. Journal of Membrane Science, 428, 380-392.

Barbiroli, A., Bonomi, F., Capretti, G., lametti, S., Manzoni, M., Piergiovanni, L., \& Rollini, M. (2012). Antimicrobial activity of lysozyme and lactoferrin incorporated in cellulose-based food packaging. Food Control, 26(2), 387-392.

Becerril, R., Manso, S., Nerin, C., \& Gómez-Lus, R. (2013). Antimicrobial activity of Lauroyl Arginate Ethyl (LAE), against selected food-borne bacteria. Food Control, 32(2), 404-408. 
Cabra, V., Arreguin, R., Galvez, A., Quirasco, M., Vazquez-Duhalt, R., \& Farres, A. (2005). Characterization of a $19 \mathrm{kDa}$ alpha-zein of high purity. Journal of Agricultural and Food Chemistry, 9(53), 725-729.

Cerisuelo, J. P., Gavara, R., \& Hernández-Muñoz, P. (2015). Antimicrobial-releasing films and coatings for food packaging based on carvacrol and ethylene copolymers. Polymer International, 16(12), 1747-1753.

del Nobile, M. A., Conte, A., Incoronato, A. L., \& Panza, O. (2008). Antimicrobial efficacy and release kinetics of thymol from zein films. Journal of Food Engineering, 89(1), 57-63.

di Gioia, L., \& Guilbert, S. (1999). Corn protein-based thermoplastic resins: Effect of some polar and amphiphilic plasticizers. Journal of Agricultural and Food Chemistry, 47(3), 1254-1261.

Gavara, R., López-Carballo, G., Hernández-Muñoz, P., Catalá, R., Muriel-Galet, V., Cerisuelo, J. P., \& Dominguez, I. (2015). Practical Guide to Antimicrobial Active Packaging. Surrey, UK: iSmithers Rapra Publishing.

Geraghty, D., Peifer, M. A., Rubenstein, I., \& Messing, J. (1981). The primary structure of a plant storage protein: zein. Nucleic Acids Research, 9(19), 5163-5174.

Ghanbarzadeh, B., Oromiehie, A., Musavi, M., Razmi, E., \& Milani, J. (2006). Effect of polyolic plasticizers on rheological and thermal properties of zein resins. Iranian Polymer Journal, 15(10), 779-787.

Gioia, L. D., \& Guilbert, S. (1999). Corn protein-based thermoplastic resins: effect of some polar and amphiphilic plasticizers. Journal of Agricultural Food Chemistry, 47, 1254-1261.

Guo, M., Jin, T. Z., Wang, L., Scullen, O. J., \& Sommers, C. H. (2014). Antimicrobial films and coatings for inactivation of Listeria innocua on ready-to-eat deli turkey meat. Food Control, 40, 64-70.

Guo, M., Jin, T. Z., \& Yang, R. (2014). Antimicrobial Polylactic Acid Packaging Films against Listeria and Salmonella in Culture Medium and on Ready-to-Eat Meat. Food and Bioprocess Technology, 7(11), 3293-3307.

Hawkins, D. R., Rocabayera, X., Ruckman, S., Segret, R., \& Shaw, D. (2009). Metabolism and pharmacokinetics of ethyl Na-lauroyl-L-arginate hydrochloride in human volunteers. Food and Chemical Toxicology, 47(11), 2711-2715.

Herald, T. J., Hachmeister, K. A., Huang, S., \& Bowers, J. R. (1996). Corn zein packaging materials for cooked turkey. Journal of Food Science, 61 (2), 415-418.

Higueras, L., López-Carballo, G., Hernández-Muñoz, P., Gavara, R., \& Rollini, M. (2013). Development of a novel antimicrobial film based on chitosan with LAE (ethyl-N $\alpha$-dodecanoyl-I-arginate) and its application to fresh chicken. International Journal of Food Microbiology, 165(3), 339345.

Hosseini, S. F., Rezaei, M., Zandi, M., \& Ghavi, F. F. (2013). Preparation and functional properties of fish gelatin-chitosan blend edible films. Food Chemistry, 136(3-4), 1490-1495.

Janes, M. E., Kooshesh, S., \& Johnson, M. G. (2002). Control of Listeria monocytogenes on the surface of refrigerated, ready-to-eat chicken coated with edible zein WIm coatings containing nisin and/ or calcium propionate. Journal of Food Science, 67(7), 2754-2757.

Liang, J., Xia, Q., Wang, S., Li, J., Huang, Q., \& Ludescher, R. D. (2015). Influence of glycerol on the molecular mobility, oxygen permeability and microstructure of amorphous zein films. Food Hydrocolloids, 44, 94-100.

Luchansky, J. B., Call, J. E., Hristova, B., Rumery, L., Yoder, L., \& Oser, A. (2005). Viability of Listeria monocytogenes on commercially-prepared hams surface treated with acidic calcium sulfate and lauric arginate and stored at 4degreesC. Meat Science, 71(1), 92-99.

Madeka, H., \& Kokini, J. L. (1996). Effect of glass transition and cross-linking on rheological properties of zein: Development of a preliminary state diagram. Cereal Chemistry, 73(4), 433-438.

Martins, J. T., Cerqueira, M. A., \& Vicente, A. A. (2012). Influence of $\alpha$-tocopherol on physicochemical properties of chitosan-based films. Food Hydrocolloids, 27(1), 220-227.

Mastromatteo, M., Barbuzzi, G., Conte, A., \& Del Nobile, M. A. (2009). Controlled release of thymol from zein based film. Innovative Food Science \& Emerging Technologies, 10(2), 222-227. 
Matsushima, N., Danno, G.-i., Takezawa, H., \& Izumi, Y. (1997). Three-dimensional structure of maize $\alpha$-zein proteins studied by small-angle X-ray scattering. Biochimica et Biophysica Acta (BBA) Protein Structure and Molecular Enzymology, 1339(1), 14-22.

McHugh, T. H., \& Krochta, J. (1994). Permeability properties of edible films. In E. A. Baldwin, R. Hagenmaier, J. Bai \& J. M. Krochta (Eds.), Edible Coatings and Films to Improve Food Quality (pp. 139-187): Taylor \& Francis.

Muriel-Galet, V., Cerisuelo, J. P., López-Carballo, G., Lara, M., Gavara, R., \& Hernández-Muñoz, P. (2012). Development of antimicrobial films for microbiological control of packaged salad. International Journal of Food Microbiology, 157(2), 195-201.

Muriel-Galet, V., Lopez-Carballo, G., Gavara, R., \& Hernandez-Munoz, P. (2015). Antimicrobial Effectiveness of Lauroyl Arginate Incorporated into Ethylene Vinyl Alcohol Copolymers to Extend the Shelf-Life of Chicken Stock and Surimi Sticks. Food and Bioprocess Technology, 8(1), 208-217.

Muriel-Galet, V., López-Carballo, G., Hernández-Muñoz, P., \& Gavara, R. (2014). Characterization of ethylene-vinyl alcohol copolymer containing lauril arginate (LAE) as material for active antimicrobial food packaging. Food Packaging and Shelf Life, 1(1), 10-18.

Muriel Galet, V., Cerisuelo, J., Lopez Carballo, G., Aucejo, S., Gavara, R., \& Hernández Muñoz, P. (2013). Evaluation of EVOH-coated PP films with oregano essential oil and citral to improve the shelf-life of packaged salad. Food Control, 30(1), 137-143.

Naushad Emmambux, M., \& Stading, M. (2007). In situ tensile deformation of zein films with plasticizers and filler materials. Food Hydrocolloids, 21(8), 1245-1255.

Otero, V., Becerril, R., Santos, J. A., Rodríguez-Calleja, J. M., Nerín, C., \& García-López, M.-L. (2014). Evaluation of two antimicrobial packaging films against Escherichia coli 0157:H7 strains in vitro and during storage of a Spanish ripened sheep cheese (Zamorano). Food Control, 42(0), 296-302.

Ozcalik, O., \& Tihminlioglu, F. (2013). Barrier properties of corn zein nanocomposite coated polypropylene films for food packaging applications. Journal of Food Engineering, 114(4), 505-513.

Petersen, K., Nielsen, P. V., Bertelsen, G., Lawther, M., Olsen, M. B., Nilsson, N. H., \& Mortensen, G. (1999). Potential of biobased materials for food packaging. Trends in Food Science \& Technology, 10(2), 52-68.

Singh, N., Georget, D. M. R., Belton, P. S., \& Barker, S. A. (2010). Physical properties of zein films containing salicylic acid and acetyl salicylic acid. Journal of Cereal Science, 52(2), 282-287.

Yamada, K., Takahashi, H., \& Noguchi, A. (1995). Improved water resistance in edible zein films and composites for biodegradable food packaging. International Journal of Food Science and Technology, 30(5), 599-608. 


\section{LEGENDS TO FIGURES}

513

514 Figure 1. DSC thermograms of the various zein samples with indication of $\mathrm{Tg}$ values. $\mathrm{Tg}$

515 values with different letters are significantly different $(\mathrm{P}<0.05)$.

516 Figure 2. Water gain during the water vapor transmission experiment at the two humidity

517 gradients tested (left figure). Water vapor permeability of zein films with different LAE

518 levels (right figure). Values with different letters are significantly different $(\mathrm{P}<0.05)$.

519

520 Figure 3. Oxygen permeability values for the zein-based film samples at $23{ }^{\circ} \mathrm{C}$ and 0,70 , and $52190 \%$ RH.

522 Figure 4. Relative release of LAE from Zein-G-5\%LAE and Zein-G-10\%LAE into 10\% $523 \mathrm{EtOH}$ at 4,23 , and $37^{\circ} \mathrm{C}$. Symbols are experimental data, lines are obtained by curve fitting 524 following the appropriate resolution to Fick's equation (described in the supplementary file).

525 Figure 5. Percentage of LAE released from films into the various simulants at equilibrium

526 (left image) and Arrhenius plots of the diffusion coefficient values for LAE in zein films

527 exposed to the three simulants considered, including the activation energies for the diffusion

$528\left(\mathrm{E}_{\mathrm{a}}\right)$. Different letters indicate that for a simulant, percentage values are affected by

529 temperature, different numbers indicate that for a temperature percentage values are affected

530 by the simulant $(\mathrm{P}<0.05)$.

531

532

533 

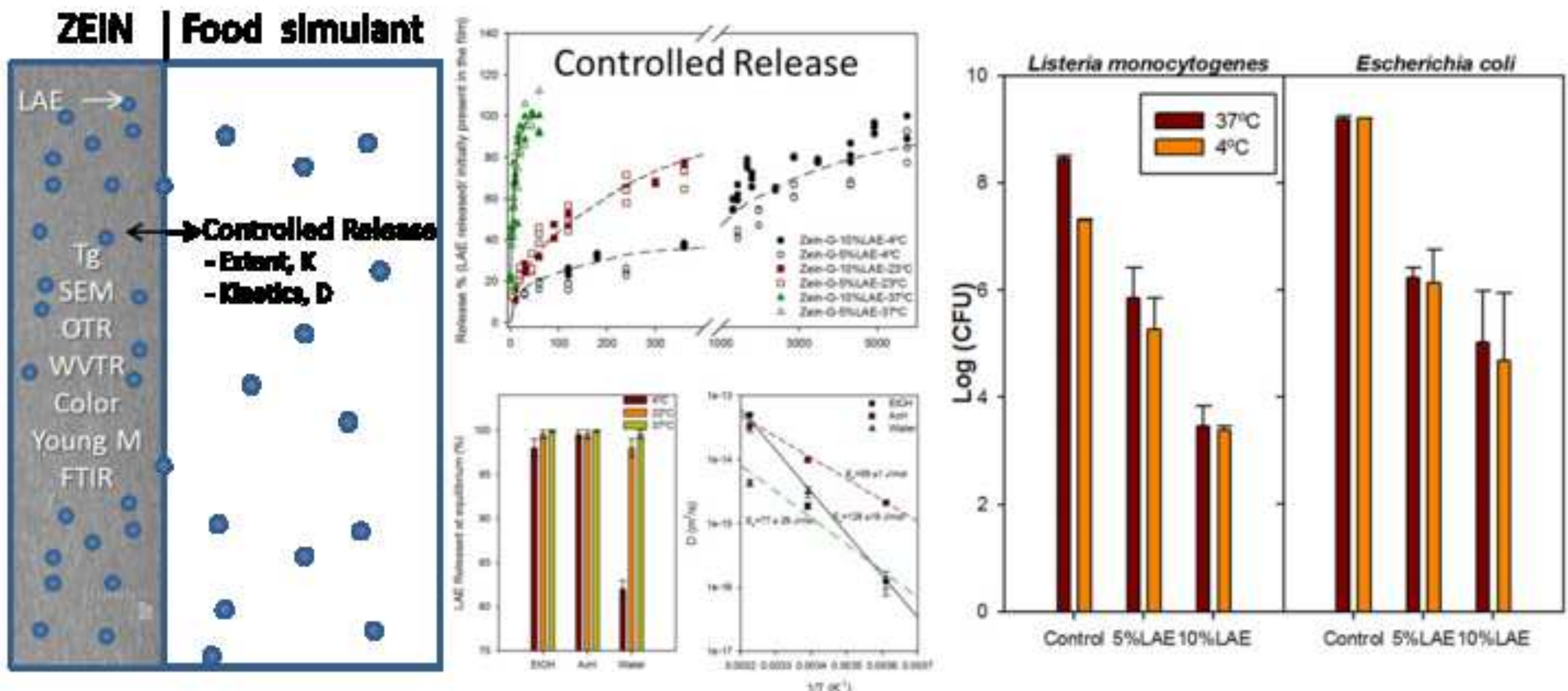


\section{Highlights}

LAE successfully incorporated into water-resistant homogeneous zein films

LAE addition up to $10 \%$ do not alter substantially zein film functional properties

LAE is released into aqueous food simulants in a Fickian controlled process

LAE release from films efficiently inhibit the growth of L. monocytogenes and E. coli 


\section{LEGENDS TO FIGURES}

Figure 1. DSC thermograms of the various zein samples with indication of Tg values. $\mathrm{Tg}$ values with different letters are significantly different $(\mathrm{P}<0.05)$.

Figure 2. Water gain during the water vapor transmission experiment at the two humidity gradients tested (left figure). Water vapor permeability of zein films with different LAE levels (right figure). Values with different letters are significantly different $(\mathrm{P}<0.05)$.

Figure 3. Oxygen permeability values for the zein-based film samples at $23{ }^{\circ} \mathrm{C}$ and 0 , 70 , and $90 \% \mathrm{RH}$.

Figure 4. Relative release of LAE from Zein-G-5\%LAE and Zein-G-10\%LAE into 10\% $\mathrm{EtOH}$ at 4,23 , and $37^{\circ} \mathrm{C}$. Symbols are experimental data, lines are obtained by curve fitting following the appropriate resolution to Fick's equation (described in the supplementary file).

Figure 5. Percentage of LAE released from films into the various simulants at equilibrium (left image) and Arrhenius plots of the diffusion coefficient values for LAE in zein films exposed to the three simulants considered, including the activation energies for the diffusion $\left(E_{a}\right)$. Different letters indicate that for a simulant, percentage values are affected by temperature, different numbers indicate that for a temperature percentage values are affected by the simulant $(\mathrm{P}<0.05)$. 


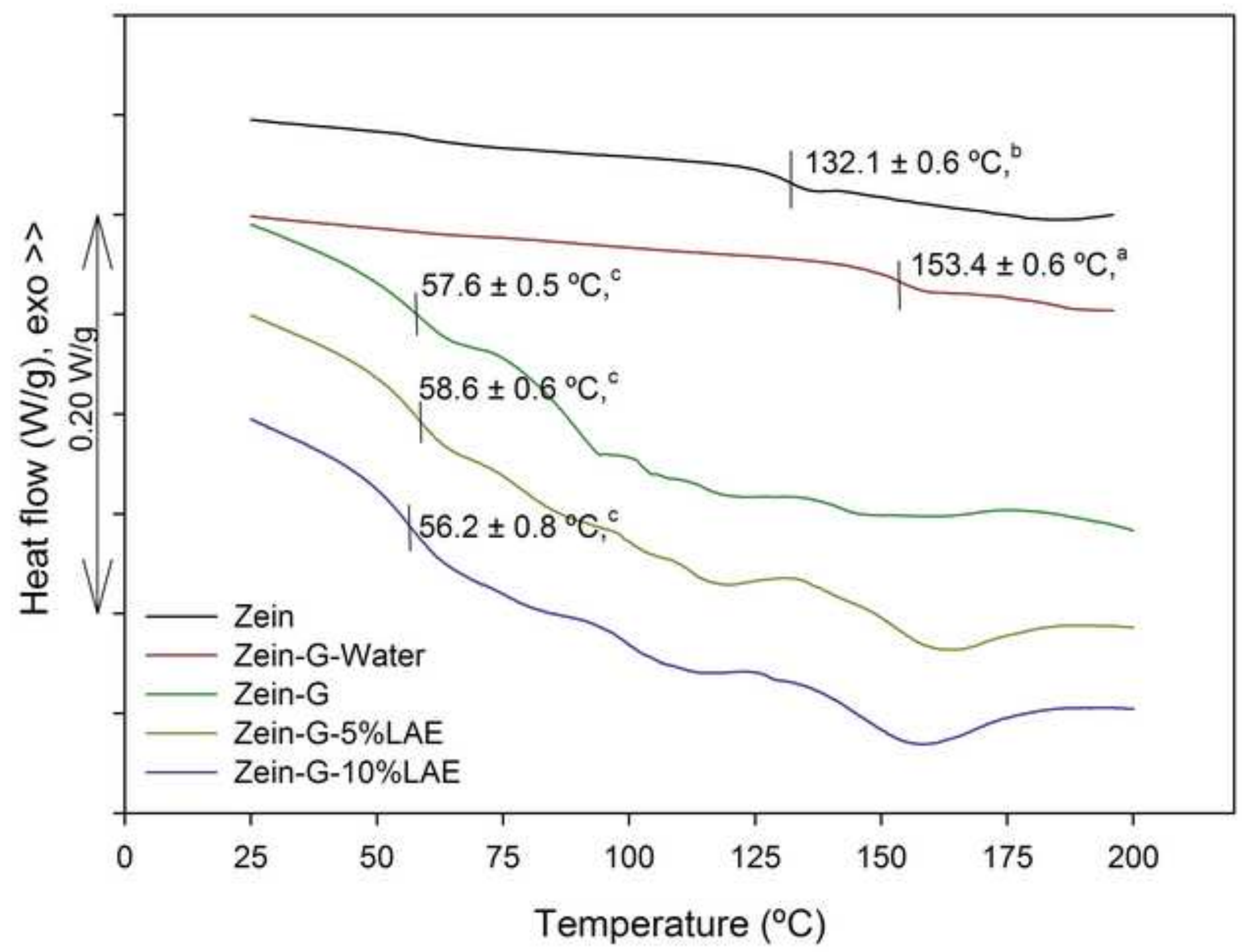



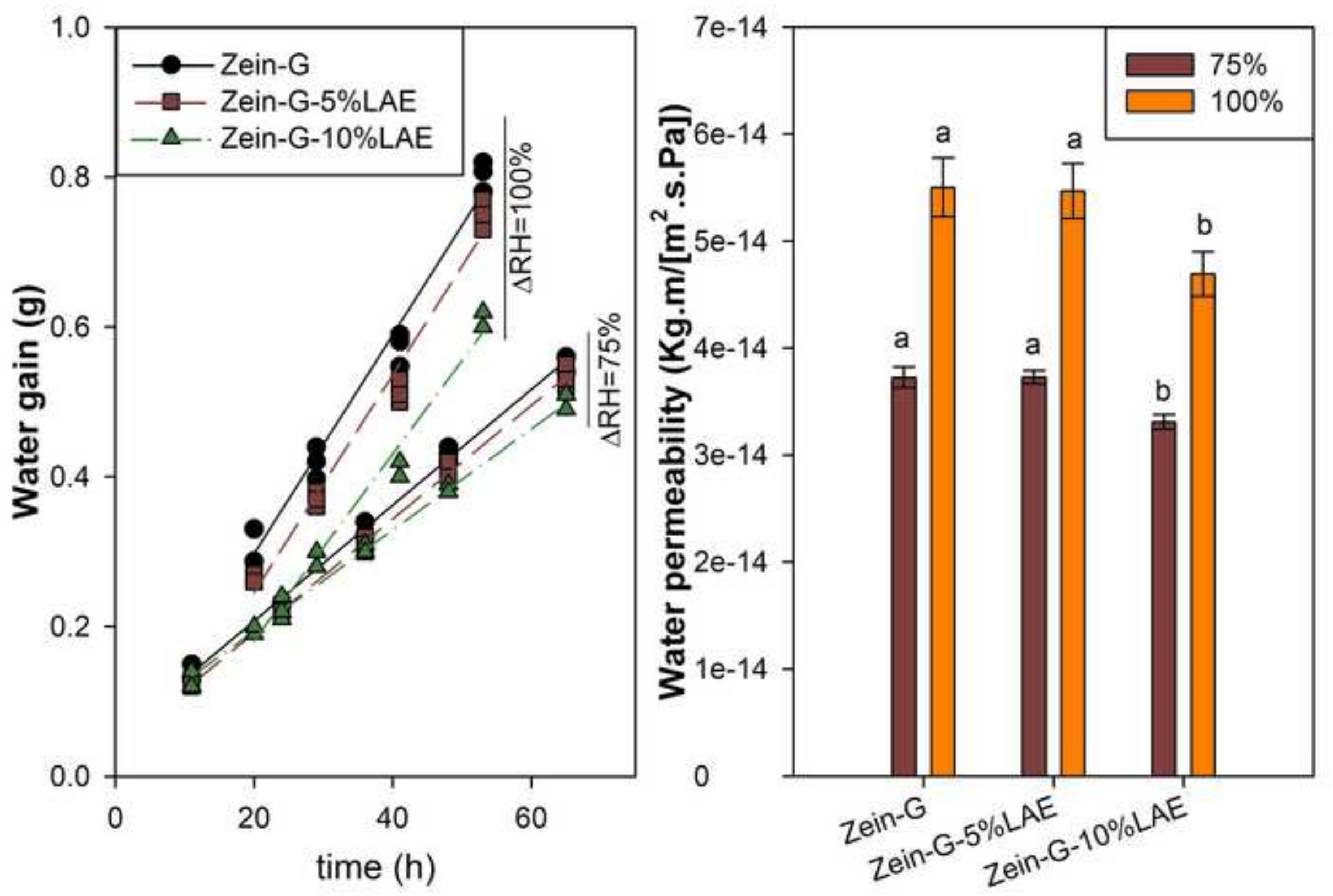


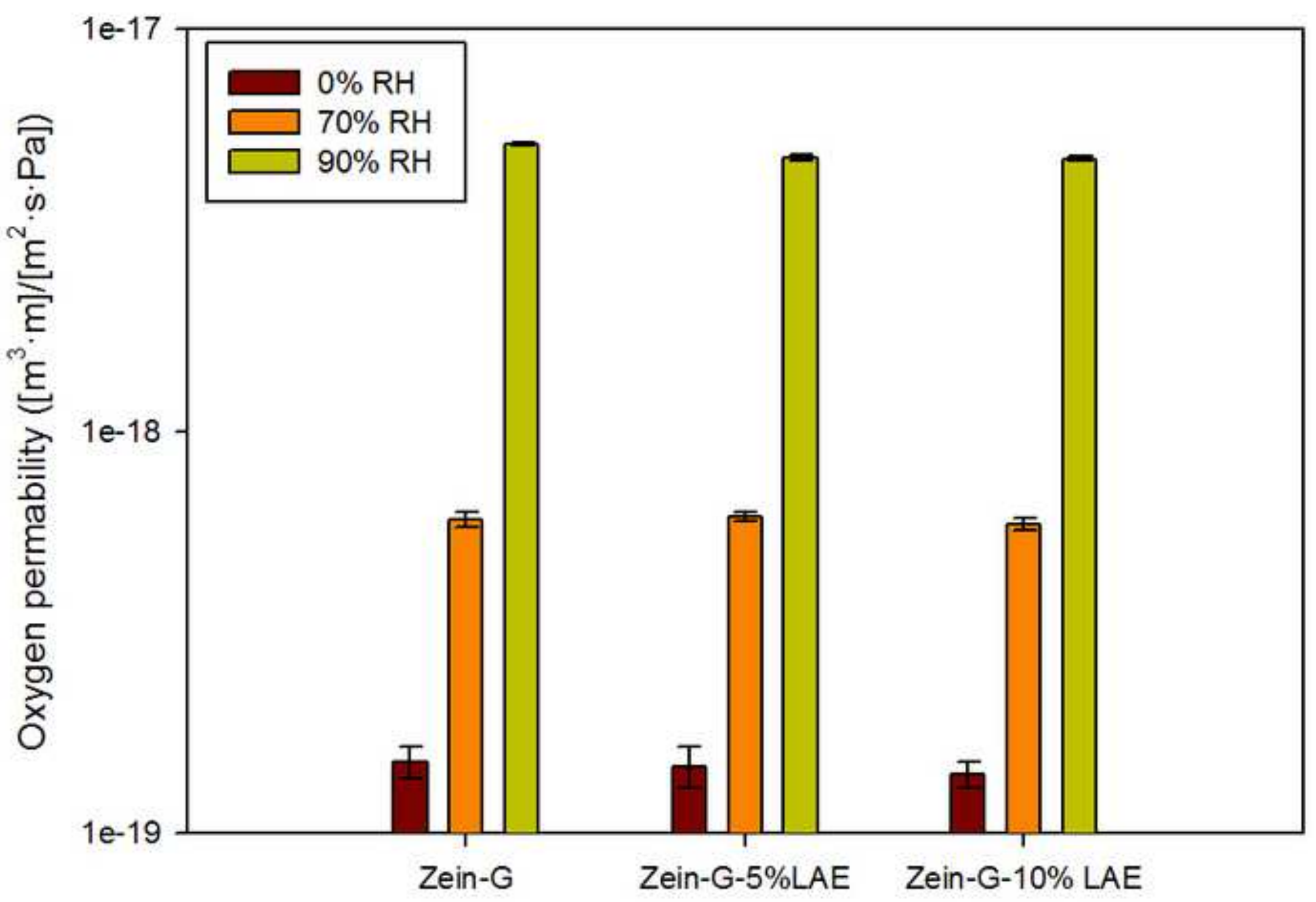




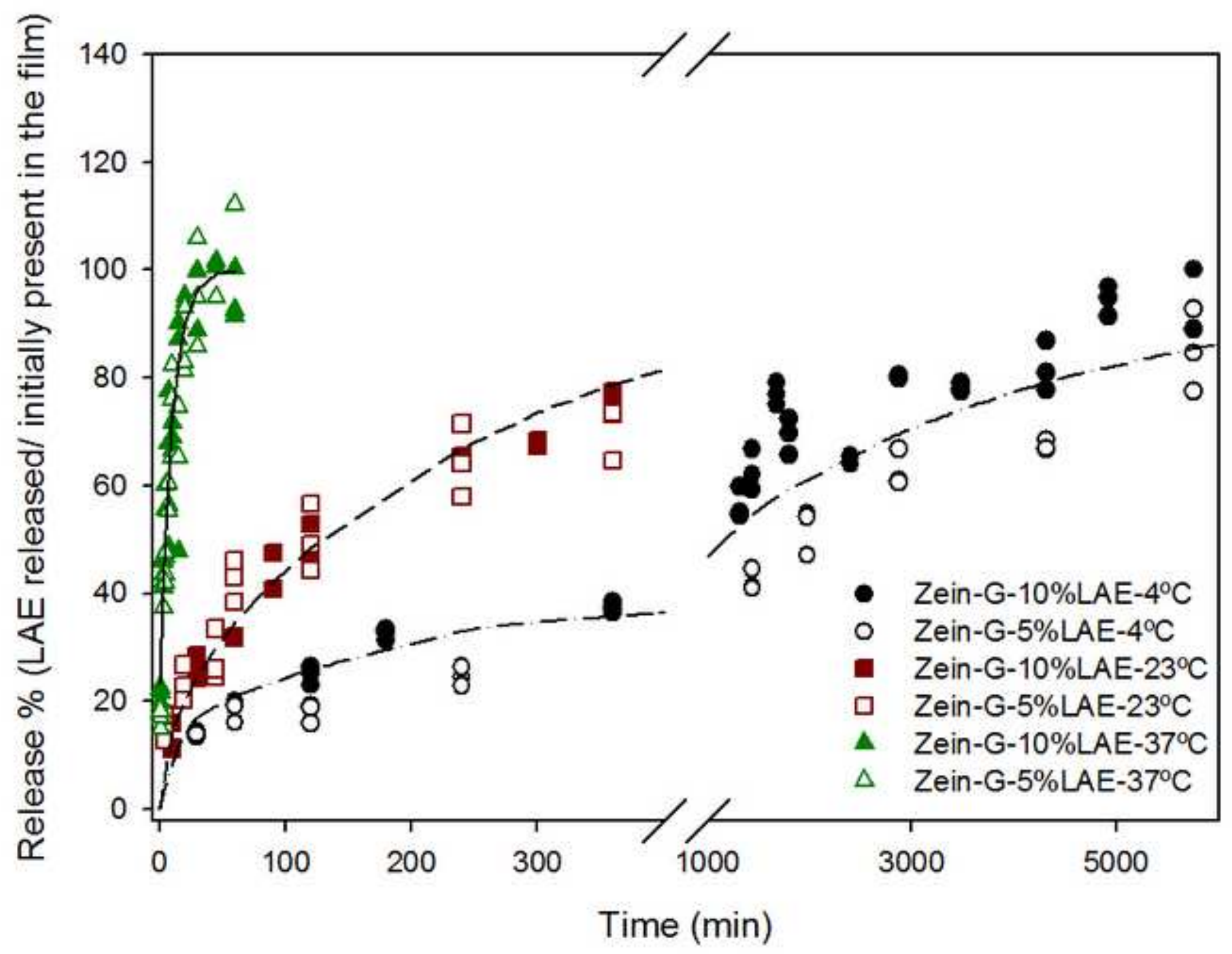



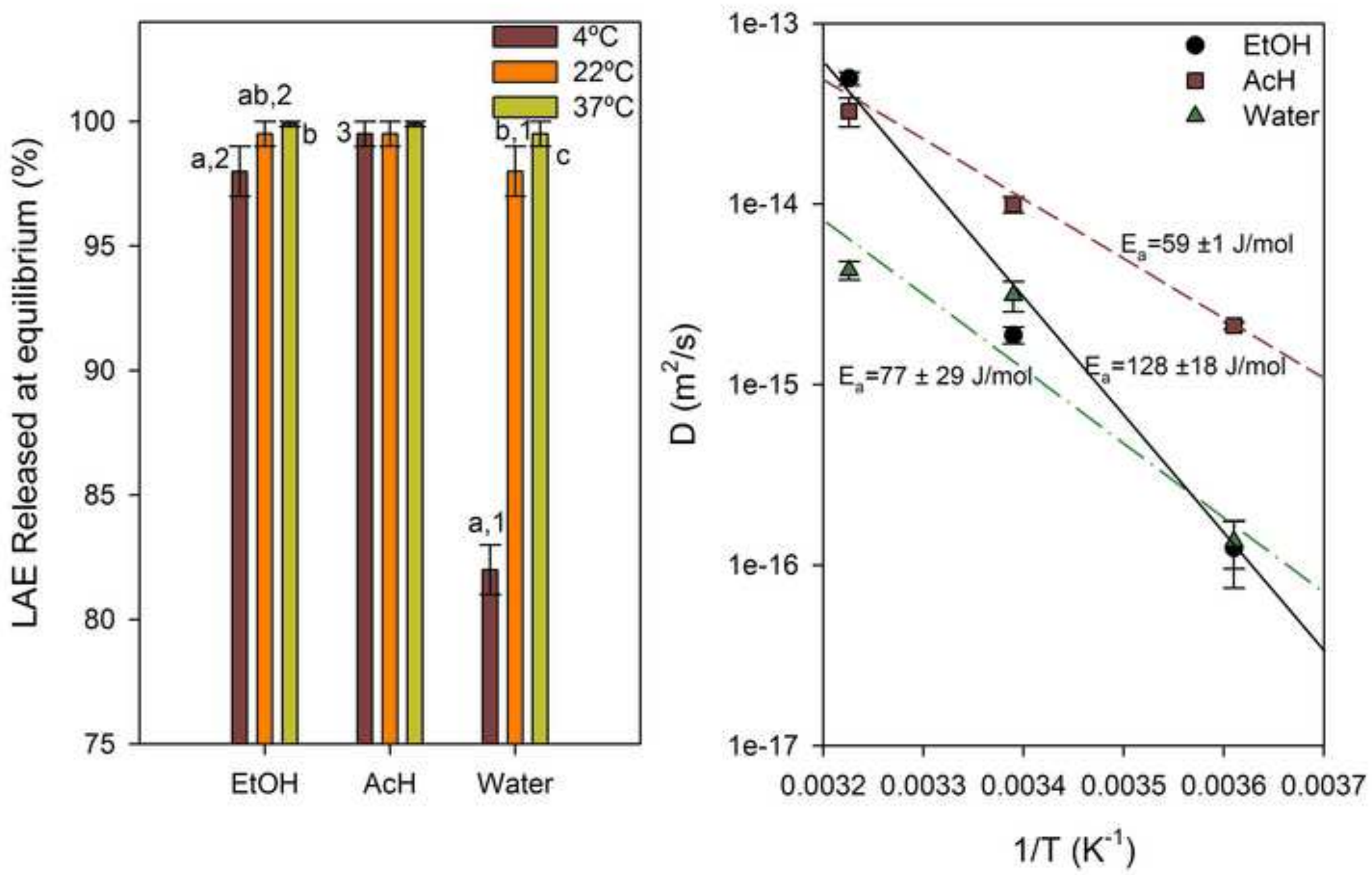
Table 1. Antimicrobial effectiveness of LAE films against L. monocytogenes and E. coli at $37{ }^{\circ} \mathrm{C}$ for $18 \mathrm{~h}$ and $4{ }^{\circ} \mathrm{C}$ for 5 days Values expressed as logarithm of colony forming units (log CFU/mL) and $\log$ reduction value (LRV).

\begin{tabular}{|c|c|c|c|c|c|c|c|c|}
\hline Film sample & \multicolumn{4}{|c|}{ L. monocytogenes } & \multicolumn{3}{c|}{ E. coli } \\
\hline & \multicolumn{2}{|c|}{$37^{\circ} \mathrm{C}$} & \multicolumn{2}{c|}{$4^{\circ} \mathrm{C}$} & \multicolumn{2}{c|}{$37^{\circ} \mathrm{C}$} & \multicolumn{2}{c|}{$4^{\circ} \mathrm{C}$} \\
\hline & $\log \left(\frac{C F U}{m L}\right)$ & $L R V$ & $\log \left(\frac{C F U}{m L}\right)$ & $L R V$ & $\log \left(\frac{C F U}{m L}\right)$ & $L R V$ & $\log \left(\frac{C F U}{m L}\right)$ & $L R V$ \\
\hline Zein-G & $8.46 \pm 0.05$ & & $7.30 \pm 0.03$ & & $9.19 \pm 0.05$ & & $9.20 \pm 0.01$ & \\
\hline Zein-G-5\%LAE & $5.85 \pm 0.57$ & 2.61 & $5.27 \pm 0.59$ & 2.02 & $6.23 \pm 0.19$ & 2.95 & $6.13 \pm 0.62$ & 3.07 \\
\hline
\end{tabular}




\section{Supplementary Material}

\section{Novel antimicrobial biopolymer Zein film for controlled release of lauroyl arginate}

(LAE)

Mahboobeb Kashiri ${ }^{1}$, Josep P. Cerisuelo, Irene Domínguez, Gracia López-Carballo, Pilar Hernández-Muñoz, Rafael Gavara*

Packaging Lab, Instituto de Agroquímica y Tecnología de Alimentos, CSIC, Av. Agustín Escardino 7, 46980 Paterna (SPAIN), rgavara@iata.csic.es

${ }^{1}$ Present address: Department of Food Science and Technology, Gorgan University of Agricultural Sciences and Natural Resources, Beheshti Ave., Gorgan 49138-15739, Iran

\section{EXPERIMENTAL SECTION}

\subsection{Film preparation}

Zein powder was dissolved in a hydroalcoholic solution $(80 \% \mathrm{v} / \mathrm{v})$ to obtain $16 \%(\mathrm{w} / \mathrm{w})$ film-forming solutions. The solution was stirred for $30 \mathrm{~min}$ at $70{ }^{\circ} \mathrm{C}$ using a magnetic stirrer hotplate and with the use of a reflux vapor system. Due to the fragility of the zein film, the addition of glycerol as plasticizer was required, otherwise the film could not be handled. Glycerol was added in increasing concentrations of 5\%. After the film was formed (as described below), the film was removed from the casting surface. The amount of glycerol selected was the minimum amount that made it possible to remove the film from the casting surface without breaking in three consecutive trials. Accordingly, $15 \%$ glycerol (w/w of zein) was added to the solution and it was stirred again for 8 min at $30{ }^{\circ} \mathrm{C}$. Then LAE was added to the polymer solutions at 5 and $10 \%$ with respect to polymer content and it was stirred for $8 \mathrm{~min}$. The film-forming solutions were cooled down to $40{ }^{\circ} \mathrm{C}$ and then spread on a clean glass plate using a spreading bar with a thread $250 \mu \mathrm{m}$ deep (LinLab, Logroño, Spain) and dried in a forced-air drying tunnel equipped with a $2500 \mathrm{~W}$ IR heat source for $20 \mathrm{~min}$. Then the films were peeled off and stored in desiccators until tested. Control films were prepared without active agent. Film thickness was determined individually with a digital micrometer (Mitutoyo, Kanagawa, Japan) prior to testing.

\subsection{Film characterization}




\subsubsection{Water solubility}

Samples of films $(2 \times 2 \mathrm{~cm})$ were dried in a desiccator containing phosphorus pentoxide for at least one week until a constant weight was reached $\left(\mathrm{w}_{\mathrm{i}}\right)$. Then the sample was immersed in aqueous solution buffered at $\mathrm{pH} 5$ at $23^{\circ} \mathrm{C}$. After $24 \mathrm{~h}$, film pieces were removed from the solution, wiped off with a paper towel, and dried in the desiccator until sample weight was constant (final weight, $\mathrm{w}_{\mathrm{f}}$ ). The percentage of water solubility (WS) was calculated as follows:

$$
W S(\%)=\frac{w_{i}-w_{f}}{w_{i}} \cdot 100
$$

The experiment was performed in triplicate.

\subsubsection{Optical properties}

The film color was determined with a CR-300 Minolta Chroma meter (Minolta Camera Co., Ltd., Osaka, Japan). The colorimeter was calibrated using a standard white plate $(\mathrm{L}=93.49, \mathrm{a}=-0.25, \mathrm{~b}=-$ 0.09). Then the color measurements were performed by placing the film specimens over the colorimeter. The results were expressed in accordance with the CIELAB system with reference to illuminant $\mathrm{D}_{65}$ and a visual angle of $10^{\circ}$.At least three points on each sample were selected randomly to measure the color properties of the zein films. Color parameters L* (lightness), $a^{*}$ (red/green), $b^{*}$ (yellow/blue) were measured, color difference $\left(\Delta \mathrm{E}_{\mathrm{ab}}\right)$, chroma $\left(\mathrm{C}_{\mathrm{ab}}{ }^{*}\right)$, and hue $\left(\mathrm{h}_{\mathrm{ab}}\right)$ were calculated using the following equations (Higueras, López-Carballo, Cerisuelo, Gavara \& Hernández-Muñoz, 2013 ).

$$
\begin{aligned}
& \Delta \mathrm{E}_{\mathrm{ab}}=\sqrt{(\Delta \mathrm{L})^{2}+(\Delta \mathrm{a})^{2}+(\Delta \mathrm{b})^{2}}, \text { where } \Delta \mathrm{L}=\left(\mathrm{L}^{*}-\mathrm{L}\right), \Delta \mathrm{a}=\left(\mathrm{a}^{*}-\mathrm{a}\right), \Delta \mathrm{b}=\left(\mathrm{b}^{*}-\mathrm{b}\right)(2) \\
& \mathrm{C}_{\mathrm{ab}}^{*}=\sqrt{\left(\mathrm{a}^{* 2}+\mathrm{b}^{* 2}\right)} \\
& \mathrm{h}_{\mathrm{ab}}=\operatorname{Arctan}\left(\frac{\mathrm{b}^{*}}{\mathrm{a}^{*}}\right)
\end{aligned}
$$

The apparent transparency was evaluated, using a UV-visible spectrophotometer (Agilent, 8453, Barcelona, Spain), as the integrated area under the curve, which was calculated using UV-WIN-Lab software and expressed as the product of absorbance value (A) and wavelength (nm). Samples were measured in triplicate.

\subsubsection{Mechanical properties}


Tensile strength (TS), percentage of elongation at break (EB), and Young's modulus (YM) of the films (preconditioned at $50 \pm 5 \% \mathrm{RH}$ at room temperature for at least 24 hours prior to testing) were determined using a Mecmesin MultiTest 1-I universal machine (Landes Poli Ibércia, S.L., Barcelona, Spain) according to ASTM D882(ASTM, 2009). Film samples were cut into rectangular strips (2.54 $\times 10 \mathrm{~cm}$ ) and mounted between the tensile grips of the instrument. The initial grip spacing and crosshead speed were set at $5 \mathrm{~cm}$ and $25 \mathrm{~mm} \mathrm{~min}^{-1}$ respectively. The tensile properties were calculated from the plot of stress (tensile force/initial cross-section area) versus strain (elongation as a fraction of the original length). All determinations are the means of at least 8 measurements.

\subsubsection{Water vapor permeability (WVP)}

The water vapor permeability through the films was determined gravimetrically at $25{ }^{\circ} \mathrm{C}$ according to ASTM E96-95(ASTM, 2010). The cup had an internal diameter of $3.5 \mathrm{~cm}$ and an external diameter of $4.5 \mathrm{~cm}$ (exposed area: $7.065 \mathrm{~cm}^{2}$ ), and was $3.5 \mathrm{~cm}$ deep. The cup was filled with $7 \mathrm{~g}$ of silica in order to generate a $0 \% \mathrm{RH}$ internal environment, and the films were fixed on top of it. A rubber O-ring and silicon grease helped to ensure a good seal. The film and rubber O-ring were attached to the cup by an aluminum annulus and three metal clips. Then the cups were placed in desiccators containing saturated solutions of $\mathrm{NaCl}(75 \% \mathrm{RH})$ or water $(100 \% \mathrm{RH})$. Cups under test were periodically weighed in an analytical balance. When the relationship between weight loss and time was linear, the slope of the plot was used to calculate the water vapor permeability as follows:

$$
\mathrm{WVP}=\frac{\mathrm{dw}}{\mathrm{A} \cdot \mathrm{dt}} \cdot \frac{L_{\text {film }}}{\Delta P}=\mathrm{WVTR} \frac{L_{\text {film }}}{\nabla P}
$$

where WVTR is the water vapor transmission rate through a film, calculated from the slope of the straight line divided by the exposed film area, $\mathrm{L}$ is the mean film thickness, and $\Delta \mathrm{P}$ is the partial water vapor pressure difference across the two sides of the film. Three replicates of each film were tested.

\subsubsection{Determination of oxygen and carbon dioxide permeability}

The measurements of $\mathrm{O}_{2}$ and $\mathrm{CO}_{2}$ permeance through the film samples were carried out using isostatic methods (Cerisuelo, Gavara \& Hernández-Muñoz, 2015). The $\mathrm{O}_{2}$ permeation rates of the materials were determined at 0,70 , and $90 \% \mathrm{RH}$ and $23{ }^{\circ} \mathrm{C}$ using an OXTRAN Model 2/21 ML Mocon (Lippke, Neuwied, Germany). Samples were positioned in the permeation cells of the instrument and conditioned under nitrogen at the relative humidity of the test for at least 48 hours. After this preconditioning period, the runs started and were continued until three consecutive measurement cycles of 40 min showed constancy. 
The $\mathrm{CO}_{2}$ permeation rates of the materials were determined at 0,70 , and $90 \% \mathrm{RH}$ and $23{ }^{\circ} \mathrm{C}$ using a two-chamber cell and an assembly that makes use of a gas chromatograph as detector. As in the case of oxygen, samples were preconditioned at the humidity of the experiment for at least $48 \mathrm{~h}$. Analysis was carried out twice a day. The final $\mathrm{CO}_{2}$ transmission rate was obtained when 4 consecutive measurements provided a constant value.

\subsubsection{Differential scanning calorimetry (DSC)}

Differential scanning calorimetry (DSC) measurements were performed with a Q2000 unit (TA Instruments, USA) previously calibrated with indium. Film samples were cut into small pieces and put in a desiccator with phosphorus pentoxide for one week, and then ca. $30 \mathrm{mg}$ was weighed in aluminum hermetic pans and closed with the corresponding aluminum lid. The samples were cooled down to $-60{ }^{\circ} \mathrm{C}$ and after $5 \mathrm{~min}$, they were heated to $220{ }^{\circ} \mathrm{C}$ at $10{ }^{\circ} \mathrm{C} \mathrm{min}^{-1}$ heating rate under a nitrogen atmosphere. Information on the thermogram was extracted with the instrument software (TA Universal Analysis).

\subsubsection{Fourier-transform infrared (FTIR) spectroscopy}

Zein films prepared in this work were analyzed in an infrared spectrometer (FTIR) (PerkinElmer 16 PC spectrometer, Boston, USA), in Attenuated Total Reflectance mode (ATR) between 400 and $4000 \mathrm{~cm}^{-1}$, using 16 scans at a resolution of $4 \mathrm{~cm}^{-1}$.

\subsubsection{Scanning Electron Microscopy (SEM)}

Morphological changes in cross-sections of films resulting from exposure to food simulant were studied by scanning electron microscopy (SEM). Samples were prepared as follows: Active zein films were treated with acetic acid $(3 \mathrm{~mL} / 100 \mathrm{~mL}$ water $)$, ethanol $(10 \mathrm{~mL} / 100 \mathrm{~mL}$ water $)$, and deionized water for 8 hour at room temperature. After the treatment the samples were dried in a desiccator, and then they were frozen in liquid nitrogen and fractured. A double-sided copper tape was used to fix the film to the surface of an aluminum cube to observe the morphology of the cryofractured section. SEM images of treated films were compared with untreated ones. Control films without the antimicrobial substance were also observed.

\subsection{Release studies of active zein films}


The release of active compound from the zein films was investigated by immersing film samples $\left(3 \mathrm{~cm}^{2}\right)$ into $5 \mathrm{~mL}$ of food simulants. Water and two types of food simulants (in accordance with European legislation (Directive 58/572/ECC)), acetic acid (3\% v/v) and ethanol (10\% v/v), were selected. Sample tubes were stored at 4 and $37{ }^{\circ} \mathrm{C}$, and gently agitated in a shaker. Pieces of film were removed from the sample at different time intervals and the food simulant was filtered and analyzed by HPLC. Analyses were continued until an equilibrium value was reached. The concentration of LAE released in the food simulants was evaluated by HPLC (Agilent 1200 series) equipped with a DAD. The chromatographic column used was a $\mathrm{C}_{18}$ reverse phase column, $150 \mathrm{~mm}$ $\times 3.9 \mathrm{~mm}$, particle size $5 \mu \mathrm{m}$. The mobile phase was a linear gradient elution with acetonitrile:water 50:50 (v/v) containing $0.1 \%$ trifluoroacetic acid. The flowrate was $1 \mathrm{~mL} / \mathrm{min}$ and the injection volume was $20 \mu \mathrm{L}$. The LAE elution time was about 6 min and the peak area at $205 \mathrm{~nm}$ was monitored. A calibration curve was constructed previously by analyzing LAE standard solutions from 5 to $100 \mathrm{ppm}$. Analyses were carried out in triplicate. Film thickness was determined before each test and the data corrected to an average film thickness of $30 \mu \mathrm{m}$.

\subsection{Mathematical models}

A release process is fully described by the kinetics of the agent diffusion in each phase (expressed by the diffusion coefficient, $D$ ) and the chemical equilibrium (expressed by the partition coefficient, $K$ ). In this paper, $K$ is defined as the ratio of agent concentrations in the polymer $\left(c_{P}\right)$ to that of the contacting phase $\left(c_{S}\right)$ (Gavara \& Hernandez, 1994; Hernandez \& Gavara, 1994):

$$
K=\frac{c_{P}}{c_{S}}
$$

Considering the mass transport of a substance from a polymer packaging film (surface area $A$, thickness $L$, polymer volume $V_{P}=A L$, and initial agent concentration $c_{P}{ }^{i}$ ) into a food simulant (volume $V_{S}$ ), the mass of substance in the simulant at equilibrium $\left(m_{S}^{f}\right)$ can be obtained by a mass balance from:

$$
m_{S}^{f}=\frac{V_{S} \cdot c_{P}^{i} \cdot A \cdot L}{A \cdot L \cdot K+V_{S}}
$$

$K$ is assumed to be solely dependent on temperature $(T)$ following Van't Hoff's law:

$$
d(\ln K)=-\frac{\Delta H_{K}}{R} d\left(\frac{1}{T}\right)
$$

where $\Delta H_{K}$ is the enthalpy of the partition process and $R$ the gas constant. 
In practice, two extreme behaviors are commonly considered: 1) the transport process advances until the extraction from the plastic phase is almost complete $(\mathrm{K} \Rightarrow 0)$ (Goydan, Schwope, Reid \& Cramer, 1990), and 2) the percentage of mass released is negligible because the migrant component is less preferred by the contacting phase and/or preferentially retained by the polymer $(\mathrm{K}>>1)(\mathrm{Chang}$, Guttman, Sanchez \& Smith, 1988). The first approach is known in migration studies of residues as a worst case scenario assumption and is commonly used to overestimate real migration. In active packaging a more realistic assumption is required, and therefore, from the concentrations at equilibrium (long exposure time) in both the food (or food simulant) and the packaging film, the values of $K$ can easily be estimated.

Kinetically, the migration process depends on the diffusion of the transferred substance in both the plastic and the food product. Some reports discuss the effect of substance diffusion through the food product on the kinetics of a release process (Limm \& Hollifield, 1995; Schwope \& Reid, 1988). The theories proposed closely model real migration into solid foodstuffs although they are hardly used in the description of experimental migration data in which liquid simulants are common. As occurs in this study, diffusion in a food liquid phase is much faster than in the polymer, and migrant concentration in the liquid can be considered to be homogeneous, as if the solution were being stirred (which is actually the boundary condition of the experiment). With these considerations, the migration of a substance from a polymer film into a food simulant would be given by (Crank, 1975):

$$
\frac{m(t)}{m_{S}^{f}}=\frac{m(t) \cdot\left(A \cdot L \cdot K+V_{S}\right)}{V_{S} \cdot C_{P}^{i} \cdot A \cdot L}=1-\sum_{n=1}^{\infty} \frac{2 \alpha(1+\alpha)}{1+\alpha+\alpha^{2} q_{n}^{2}}+\exp \left(-\frac{4 \cdot D \cdot q_{n}^{2} \cdot t}{L^{2}}\right)
$$

where $D$ is Fick's diffusion coefficient and is commonly assumed to depend exclusively on $T$ according to (Hernandez \& Gavara, 1994):

$$
d(\ln D)=-\frac{E_{d}}{R} d\left(\frac{1}{T}\right)
$$

where $E_{d}$ is the activation energy for diffusion. $\alpha=V_{S} /(A K \ell)$ and $q_{n}$ are the positive solutions of the following equation:

$$
\tan \left(q_{n}\right)=-\alpha \cdot q_{n}
$$

By fitting the experimental data to equation (4), the value of $D$ can be estimated. The fitting process was carried out with the use of the Solver application of Excel 2010 and with the fitting program of Sigmaplot v. 10.0 .

\subsection{Evaluation of antimicrobial activity of zein films with LAE in a liquid medium}


To evaluate the antimicrobial efficiency of the zein films with 5and $10 \%$ LAE, they were tested against E. coli and L. monocytogenes. Prior to the experiment, a loop of each strain was transferred to $10 \mathrm{~mL}$ of TSB and incubated at $37{ }^{\circ} \mathrm{C}$ for $18 \mathrm{~h}$ to obtain early stationary phase cells. Cell cultures of each microorganism in stationary phase, with an optical density of 0.9 at $600 \mathrm{~nm}$, were diluted in TSB and incubated at $37{ }^{\circ} \mathrm{C}$ until exponential phase, corresponding to an optical density of 0.2 at 600 $\mathrm{nm}\left(10^{5} \mathrm{CFU} / \mathrm{mL}\right)$. One hundred $\mu \mathrm{l}$ of exponential phase microorganism was inoculated into tubes with $10 \mathrm{~mL}$ of TSB. A $0.25 \mathrm{~g}$ portion of film (cut into pieces measuring $1.5 \mathrm{~cm}^{2}$ ) was added to each tube in sterile conditions. The tubes were then incubated at $37{ }^{\circ} \mathrm{C}$ for $18 \mathrm{~h}$ and $4{ }^{\circ} \mathrm{C}$ for 5 days. As a control, zein film without active agent was also used in every experiment. Depending on the turbidity of the tubes, serial dilutions with peptone water were made and plated in Petri dishes with $15 \mathrm{~mL}$ of TSA culture medium. Colonies were counted after incubation at $37^{\circ} \mathrm{C}$ for $18 \mathrm{~h}$. 


\section{RESULTS}

\subsection{Film morphology}

Films were analyzed by scanning electron microscopy (SEM) to check for any difference in morphology caused by the addition of LAE. Figure S1 shows representative examples of the images obtained. All samples showed a smooth fracture surface, free of features. These images are evidence of good compatibility between film components (zein, glycerol, LAE). Even at high magnification (inserts in upper images), there is no sign of phase separation but only of a fragile fracture. It is also worth mentioning the presence of air bubbles in the films containing LAE, which might be a consequence of the surfactant activity of LAE during the stirring process. Also, we analyzed the materials after exposure to the food simulants used in this work, i.e., 3\% acetic acid (AcH), 10\% ethanol, and water. As the lower images show, after 8 hours of immersion in these liquids the surface of the films was still smooth without deterioration due to swelling or partial dissolution. Only in the case of water exposure did the images reveal a rougher surface.
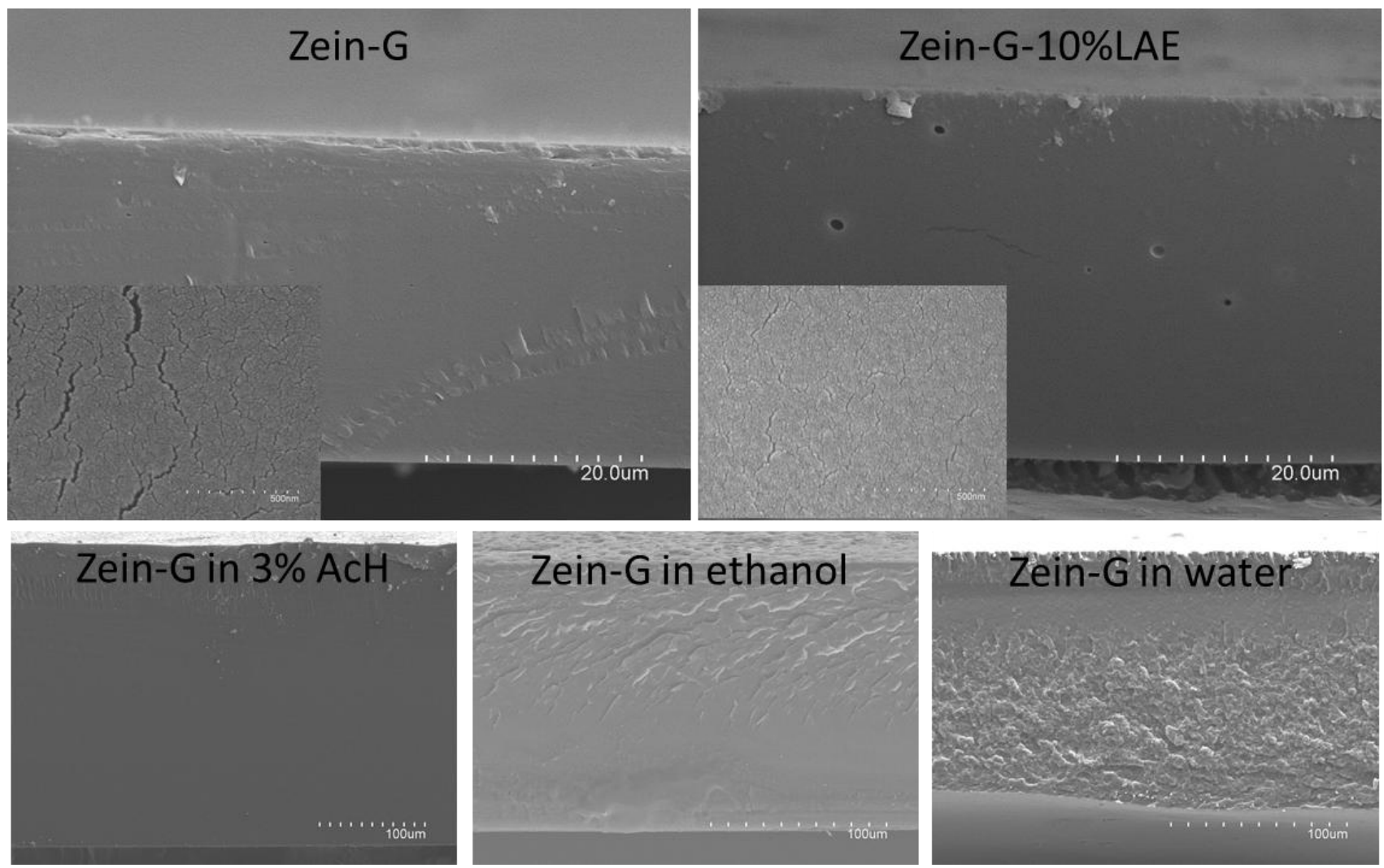

Figure S1. SEM images obtained from the cryo-fracture surface of the plasticized zein film (Zein-G), the film after exposure to various food simulants (3\% acetic acid, Zein-G in 3\% AcH; ethanol, Zein$\mathrm{G}$ in ethanol; and water, Zein-G in water), and the active film containing $10 \%$ of LAE (Zein-G$10 \% \mathrm{LAE}$ ). Inserts are detailed images of Zein-G and Zein-G-10\%LAE films. 


\subsection{Optical properties}

Color properties of films are very important in food packaging applications because they can directly affect food appearance and consumer acceptance. Visually, the zein films with 5 and 10\% LAE were transparent, flexible, and uniform, without discontinuities, and differences were not visually perceptible in comparison with the control film. The influence of LAE incorporation on the color parameter values $\left(\mathrm{L}^{*}, \mathrm{a}^{*}, \mathrm{~b}^{*}, \mathrm{c}_{\mathrm{ab}}{ }^{*}, \mathrm{~h}, \Delta \mathrm{E}\right)$ of the zein film is presented in Error! Reference source not found. The high values of $\mathrm{L}^{*}(>88)$ are indicative of good lightness of zein films; the L value of the films was increased from 88.30 to 90.90 by the addition of LAE. The surfactant capacity of this compound might improve the homogeneity of the film and surface gloss.

Table S1. Color parameter values of zein films with different amounts of LAE

\begin{tabular}{|l|c|c|c|c|c|c|}
\hline Film type & $L^{*}$ & $a^{*}$ & $b^{*}$ & $C_{a b^{*}}$ & $h_{a b}$ & $\Delta E$ \\
\hline Zein-G & $88.3 \pm 0.1^{\mathrm{b}}$ & $1.85 \pm 0.02^{\mathrm{a}}$ & $6.68 \pm 0.13^{\mathrm{a}}$ & $7.00 \pm 0.13^{\mathrm{a}}$ & $105.6 \pm 0.1^{\mathrm{a}}$ & $10.15 \pm 0.07^{\mathrm{a}}$ \\
\hline Zein-G-5\%LAE & $90.5 \pm 0.2^{\mathrm{a}}$ & $1.70 \pm 0.07^{\mathrm{a}}$ & $6.23 \pm 0.21^{\mathrm{a}}$ & $6.50 \pm 0.16^{\mathrm{a}}$ & $105.4 \pm 0.2^{\mathrm{a}}$ & $8.10 \pm 1.03^{\mathrm{b}}$ \\
\hline Zein-G-10\%LAE & $90.9 \pm 0.4^{\mathrm{a}}$ & $1.80 \pm 0.07^{\mathrm{a}}$ & $6.67 \pm 0.20^{\mathrm{a}}$ & $7.10 \pm 0.12^{\mathrm{a}}$ & $104.5 \pm 0.1^{\mathrm{b}}$ & $8.05 \pm 1.10^{\mathrm{b}}$ \\
\hline
\end{tabular}

${ }^{\mathrm{a}}$ Data reported are mean values and standard deviations. Values within each column with different letters are significantly different $(\mathrm{P}<0.05)$.

On the other hand, the slightly negative values of $a^{*}$ and positive values of $b^{*}$ are indicative of a yellow-green color. As can be seen in Table $S 1, a^{*}$ and $b^{*}$ values of the films, as well as those of chroma $\left(\mathrm{C}_{\mathrm{ab}} *\right)$, were not significantly different; this result indicates that the color is mainly due to zein even though the material used is a decolored protein. The presence of LAE in the polymer matrix decreased $\Delta \mathrm{E}$ significantly, although the concentration of LAE did not present a significant effect. A similar effect on $\mathrm{h}_{\mathrm{ab}}$ was observed, although in this case, the difference was only significant for the film with $10 \%$ of the antimicrobial agent. 


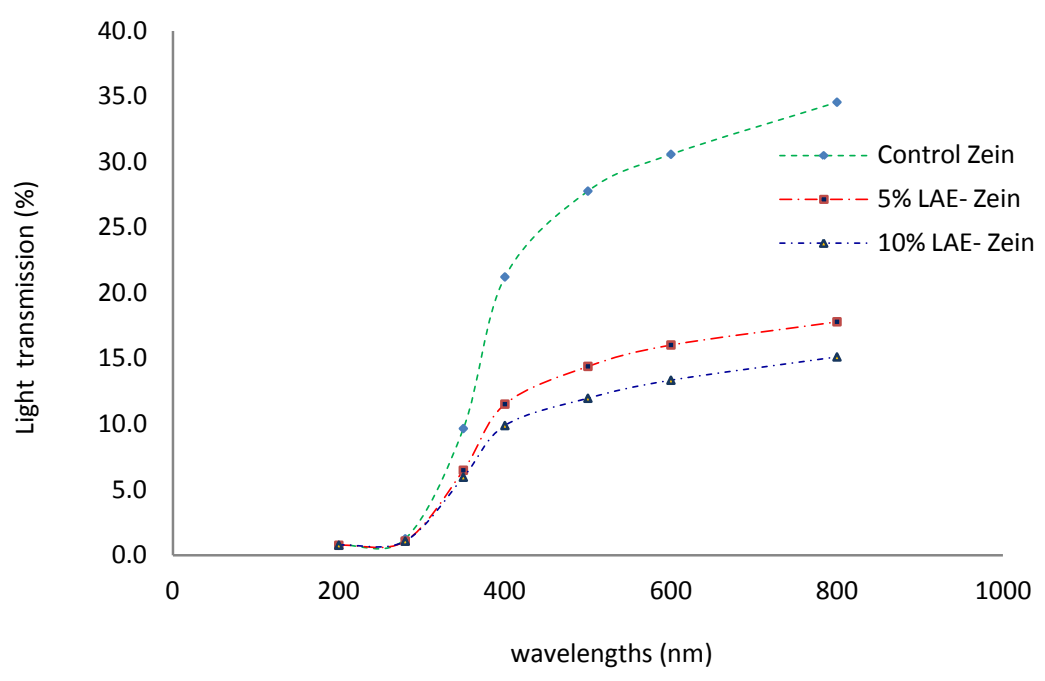

Figure S2. Light transmission characteristics for the films (control and films with LAE).

Opacity, a magnitude inversely related to transparency (Abdollahi, Alboofetileh, Behrooz, Rezaei \& Miraki, 2013), was measured by UV-visible spectrophotometry. As shown in Figure S2, light transmission of the zein films was negligible at UV wavelengths and increased in the visible regions (400-800 nm). Protein-based films are considered to have high UV barrier properties, owing to their high content of aromatic amino acids which absorb UV light (Hosseini, Rezaei, Zandi \& Ghavi, 2013). The zein films presented higher UV barrier properties than chitosan (57.70\%) and gelatin $(6.32 \%)$ films. So zein film could help to prevent oxidative deterioration of packaged foods, which is responsible for nutrient losses, discoloration, and off-flavors (Martins, Cerqueira \& Vicente, 2012). An increase in LAE concentration from 5 to $10 \%$ led to a decrease in the light transmittance (47.6 and $55.90 \%$, respectively) of the zein films in the visible regions (Figure S2).

\subsection{Mechanical properties}

Mechanical properties are very important in materials for packaging manufacture because they are related to structural integrity, which is critical to provide physical protection to the contained product. Tensile strength (TS), elongation at break (\% EB), and Young's modulus (YM) of zeinbased films were determined and the data are summarized in Error! Reference source not found. TS values and YM values are similar to those observed for plasticized zein by other authors (Gennadios, Park \& Weller, 1993) and to conventional oil-based polymer films such as polyethylene. However, the films presented very low elongation at break compared with thermoplastic films, 
indicative of fragile breakage, as was observed during the assays. As can be seen, the addition of LAE to the plasticized zein caused a reduction of TS from 19.0 MPa to values below $17 \mathrm{MPa}$ for both samples, with 5\% and 10\% LAE content, although the dispersion between specimens reduced the significance of these differences to $\mathrm{p}<0.10$. Although this TS depression appears to be accompanied by a decrease in YM and a decrease in EB, differences between samples were not significant for these parameters. These results are in agreement with the constancy of $\mathrm{Tg}$ observed in the DSC assays. Similar results were obtained by Theinsathid, Visessanguan, Kruenate, Kingcha and Keeratipibul (2012), who observed that the mechanical properties of LAE-coated PLA films were similar to those of neat PLA film.

Table S2. Mechanical properties of zein films with different LAE levels

\begin{tabular}{lccc}
\hline \multicolumn{1}{c}{ Film type } & $\begin{array}{c}\text { Tensile strength } \\
(\mathrm{MPa})\end{array}$ & $\begin{array}{c}\text { Young's modulus } \\
(\mathrm{MPa})\end{array}$ & $\begin{array}{c}\text { Elongation at break } \\
(\%)\end{array}$ \\
\hline Zein-G & $19.0 \pm 3.4^{\mathrm{b}}$ & $8.7 \pm 1.1$ & $2.68 \pm 0.17$ \\
Zein-G-5\%LAE & $16.9 \pm 2.5^{\mathrm{a}}$ & $8.9 \pm 1.1$ & $2.56 \pm 0.08$ \\
Zein-G-10\%LAE & $16.6 \pm 1.7^{\mathrm{a}}$ & $8.9 \pm 1.1$ & $2.51 \pm 0.15$
\end{tabular}

Data reported are mean values and standard deviations. Values within each column with different letters are significantly different $(\mathrm{P}<0.1)$.

\subsubsection{FTIR analysis of films}

Figure S3 shows the spectra recorded for the films. As can be seen, no important differences were observed in the zein spectra caused by the addition of LAE. The same features appear to be present in all spectra, without visual displacement of signals throughout the spectra, as could be expected from the similar chemical groups present in zein and LAE (or its components), with the strongest signals at ca. 1700,2900 , and $3300 \mathrm{~cm}^{-1}$. Also, the intensity of the bands in the $1000-1200 \mathrm{~cm}^{-1}$ range was maintained in all spectra with very few differences. The intensity of the signals increases with the incorporation of LAE, except in the $1400-1500 \mathrm{~cm}^{-1}$ range, where it decreases. These features show some proportionality with the conentration of agent, which could be used to quantify the percentage of LAE actually present after calibration with standard films, although that is beyond the scope of this work. 


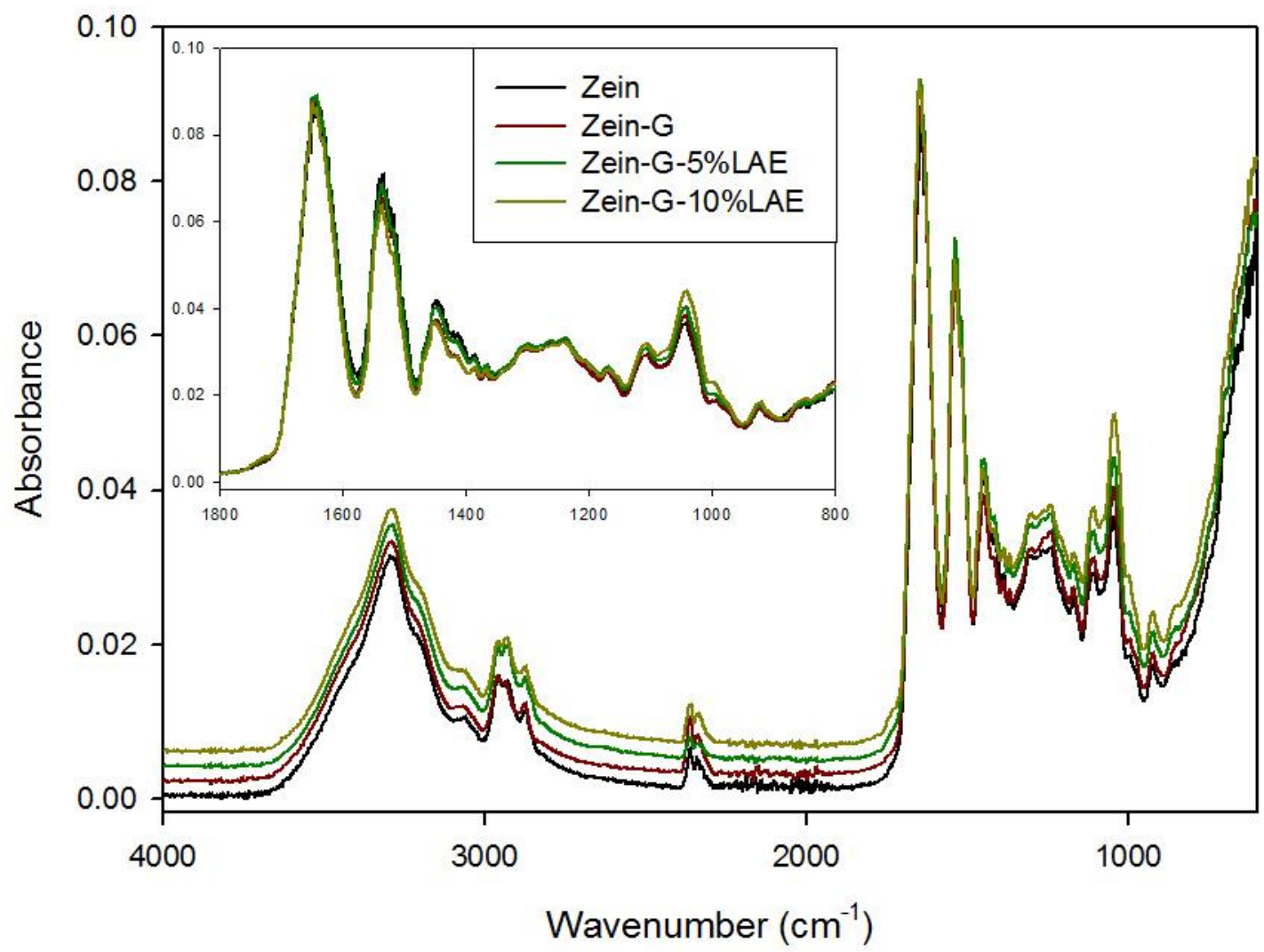

Figure S3. Spectra obtained for the various zein films developed, which have been shifted by 0.002 absorbance units for better observation. The insert includes the spectra obtained for the various materials to compare signal intensity between the films in the most relevant range.

\section{REFERENCES}

Abdollahi, M., Alboofetileh, M., Behrooz, R., Rezaei, M., \& Miraki, R. (2013). Reducing water sensitivity of alginate bio-nanocomposite film using cellulose nanoparticles. International Journal of Biological Macromolecules, 54(0), 166-173.

ASTM. (2009). Standard test method for tensile properties of thin plastic sheeting D882-02. In ASTM, Annual Book of American Standard Testing Methods. Philadelphia, PA.

ASTM. (2010). ASTM E96 / E96M - 10. Standard Test Methods for Water Vapor Transmission of Materials. In (Vol. ASTM E96 / E96M - 10). West Conshohocken, PA,: ASTM International.

Cerisuelo, J. P., Gavara, R., \& Hernández-Muñoz, P. (2015). Antimicrobial-releasing films and coatings for food packaging based on carvacrol and ethylene copolymers. Polymer International, 16(12), 1747-1753.

Chang, S. S., Guttman, C. M., Sanchez, I. C., \& Smith, L. E. (1988). THEORETICAL AND COMPUTATIONAL ASPECTS OF MIGRATION OF PACKAGE COMPONENTS TO FOOD. ACS Symposium Series, 365, 106117.

Crank, J. (1975). The mathematics of diffusion. Oxford, UK: Clarendon Press.

Gavara, R., \& Hernandez, R. J. (1994). THE EFFECT OF WATER ON THE TRANSPORT OF OXYGEN THROUGH NYLON-6 FILMS. Journal of Polymer Science Part B-Polymer Physics, 32(14), 2375-2382.

Gennadios, A., Park, H. J., \& Weller, C. L. (1993). RELATIVE-HUMIDITY AND TEMPERATURE EFFECTS ON TENSILE-STRENGTH OF EDIBLE PROTEIN AND CELLULOSE ETHER FILMS. Transactions of the ASAE, 36(6), 1867-1872. 
Goydan, R., Schwope, A. D., Reid, R. C., \& Cramer, G. (1990). HIGH-TEMPERATURE MIGRATION OF ANTIOXIDANTS FROM POLYOLEFINS. Food Additives and Contaminants, 7(3), 323-337.

Hernandez, R. J., \& Gavara, R. (1994). SORPTION AND TRANSPORT OF WATER IN NYLON-6 FILMS. Journal of Polymer Science Part B-Polymer Physics, 32(14), 2367-2374.

Higueras, L., López-Carballo, G., Cerisuelo, J. P., Gavara, R., \& Hernández-Muñoz, P. (2013 ). Preparation and characterization of chitosan/HP-cyclodextrins composites with high sorption capacity for carvacrol. Carbohydrate Polymers, 97(2), 262-268.

Hosseini, S. F., Rezaei, M., Zandi, M., \& Ghavi, F. F. (2013). Preparation and functional properties of fish gelatin-chitosan blend edible films. Food Chemistry, 136(3-4), 1490-1495.

Limm, W., \& Hollifield, H. C. (1995). EFFECTS OF TEMPERATURE AND MIXING ON POLYMER ADJUVANT MIGRATION TO CORN-OIL AND WATER. Food Additives and Contaminants, 12(4), 609-624.

Martins, J. T., Cerqueira, M. A., \& Vicente, A. A. (2012). Influence of $\alpha$-tocopherol on physicochemical properties of chitosan-based films. Food Hydrocolloids, 27(1), 220-227.

Schwope, A. D., \& Reid, R. C. (1988). MIGRATION TO DRY FOODS. Food Additives and Contaminants, 5, 445454.

Theinsathid, P., Visessanguan, W., Kruenate, J., Kingcha, Y., \& Keeratipibul, S. (2012). Antimicrobial Activity of Lauric Arginate-Coated Polylactic Acid Films against Listeria monocytogenes and Salmonella Typhimurium on Cooked Sliced Ham. Journal of Food Science, 77(2), M142-M149. 